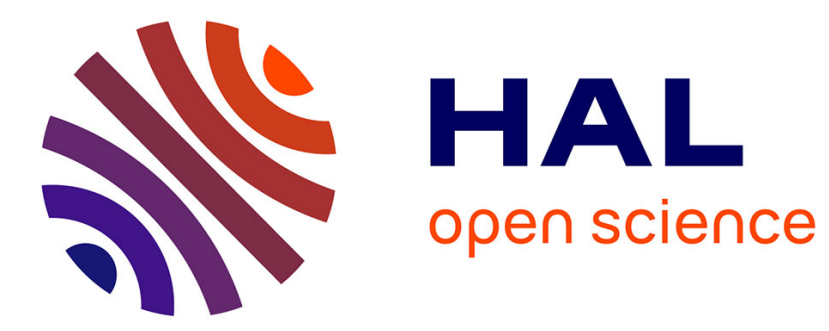

\title{
Better at Home than in Prison? The Effects of Electronic Monitoring on Recidivism in France
}

Anaïs Henneguelle, Benjamin Monnery, Annie Kensey

\section{To cite this version:}

Anaïs Henneguelle, Benjamin Monnery, Annie Kensey. Better at Home than in Prison? The Effects of Electronic Monitoring on Recidivism in France. 2016. halshs-01251347v2

HAL Id: halshs-01251347

https://shs.hal.science/halshs-01251347v2

Preprint submitted on 2 Nov 2016

HAL is a multi-disciplinary open access archive for the deposit and dissemination of scientific research documents, whether they are published or not. The documents may come from teaching and research institutions in France or abroad, or from public or private research centers.
L'archive ouverte pluridisciplinaire HAL, est destinée au dépôt et à la diffusion de documents scientifiques de niveau recherche, publiés ou non, émanant des établissements d'enseignement et de recherche français ou étrangers, des laboratoires publics ou privés. 
UMR 5824

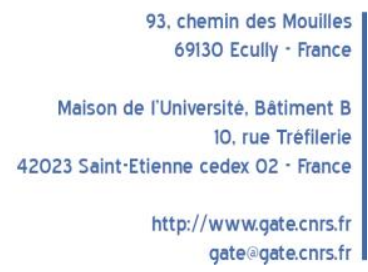

WP 1603 - January 2016. This version: September 2016

\title{
Better at Home than in Prison? \\ The Effects of Electronic Monitoring on Recidivism in France
}

\author{
Anaïs Henneguelle, Benjamin Monnery, Annie Kensey
}

\begin{abstract}
:
Many countries have recently adopted electronic monitoring (EM) as an alternative sentence in order to reduce incarceration while maintaining public safety. However, the empirical evidence on the effects of EM on recidivism (relative to prison) is very scarce worldwide. In this paper, we adress this debated question using quasi-experimental data from France. Our empirical strategy exploits the incremental roll-in of electronic monitoring in France, which started as a local experiment in four courts in 20002001, and was later adopted by more and more courts (2002-2003). Our IV estimates show that fully converting prison sentences into electronic monitoring has long-lasting beneficial effects on recidivism, with estimated reductions in probability of reconviction of 6-7 percentage points (9-11\%) after five years. There is also evidence that, in case of recidivism, EM leads to less serious offenses compared to prison. These beneficial effects are particularly strong on electronically monitored offenders who received control visits at home from correctional officers, were obliged to work while under EM, and had already experienced prison before. This pattern suggests that both rehabilitation and deterrence are important factors in reducing long-term recidivism, and that electronic monitoring can be a very costeffective alternative to short prison sentences. However, the massive development of EM in France in recent years, with shorter and less intensive supervision, may reduce its effectiveness.
\end{abstract}

\section{Keywords:}

economics of crime, prison, electronic monitoring, recidivism

JEL codes:

K42

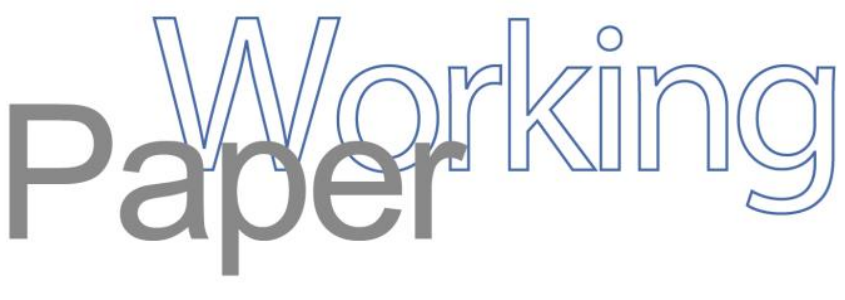




\title{
Better at Home than in Prison? \\ The Effects of Electronic Monitoring on Recidivism in France
}

Anaïs Henneguelle*

Benjamin Monnery

Annie Kensey ${ }^{\bullet}$

September 2016

\begin{abstract}
Many countries have recently adopted electronic monitoring (EM) as an alternative sentence in order to reduce incarceration while maintaining public safety. However, the empirical evidence on the effects of EM on recidivism (relative to prison) is very scarce worldwide. Our empirical strategy exploits the incremental rollout of electronic monitoring in France, which started as a local experiment in four courts in 2000-2001 and was later adopted by an increasing number of courts (2002-2003). Our IV estimates show that fully converting prison sentences into electronic monitoring has long-lasting beneficial effects on recidivism, with estimated reductions in the probability of reconviction of 6-7 percentage points (9-11\%) after five years. The presence of heterogeneous effects suggests that both rehabilitation and deterrence are important factors in reducing long-term recidivism, and that EM can be a very cost-effective alternative to short prison sentences.
\end{abstract}

JEL: K42

Keywords: economics of crime, prison, electronic monitoring, recidivism

\footnotetext{
* Ecole Normale Supérieure, Cachan ; CNRS, IDHES. anais.henneguelle@ens-cachan.fr

• Université de Lyon, Lyon, F-69007 ; CNRS, GATE, Ecully, F-69130, France. monnery@gate.cnrs.fr

- Ministère de la Justice - DAP (PMJ5); CNRS, CESDIP. annie.kensey@justice-gouv.fr

We would like to thank members of the French Prison Administration, INED and Aurélie Ouss for their work on the database. We also thank Damien Capelle, Martine Evans, Florence Gofette-Nagot, Hugo Harari-Kermadec, Nathalie Havet, Xavier Joutard, Jean-Yves Lesueur, Joseph Montag, Yves Oytana and Thomas Vendryes for useful discussions about the paper, as well as participants in various conferences and seminars : EALE (Wien), 2nd Law and Economic Policy International Workshop (Paris Ouest Nanterre), AFSE-Trésor (Paris), ETEPP (Aussois), GATE (Lyon), CES (Cachan), AFSE (Nancy).
} 


\section{Introduction}

Many countries are slowly turning away from mass incarceration in favor of new forms of punishment. In the United States for example, after three decades of steady growth, the total prison population has been declining for five consecutive years since the 2008 peak (Glaze and Kaeble, 2014). While the U.S. prison system remains by far the largest with 2.2 million inmates, a similar downward trend is currently observed among members of the Council of Europe, with their total prison population now under 1.7 million (Aebi and Chopin, 2014).

This slow decline in prison population is partly explained by budgetary and capacity constraints, but also by rising concerns about the effectiveness of incarceration. In the five years following release, $77 \%$ of ex-prisoners are re-arrested in the U.S. (Durose et al., 2014), while 59\% are re-convicted in France (Kensey and Benaouda, 2011). This context has led to the development of alternative penal sanctions which either avoid incarceration (front-door strategies) or hasten release from prison (back-door strategies). Among them, electronic monitoring (EM) is often considered as the most promising: this technology provides live surveillance of offenders ${ }^{1}$, and therefore some incapacitation and deterrence, for a tenfold decrease in operating costs (about $\$ 10$ per day under EM compared to $\$ 100$ in prison ${ }^{2}$ ). Electronic monitoring is now available in many countries, and its use is growing fast. For instance, among the five million offenders who are supervised in the community in the U.S. (Glaze and Kaeble, 2014), it is estimated that roughly 20 percent involve electronic surveillance (Gable and Gable, 2005). In England and Wales, 90,000 cases involved EM in 2012 (National Audit Office, 2013). In France, electronic surveillance concerns more than 20,000 offenders every year, compared to an

\footnotetext{
${ }^{1} \mathrm{EM}$ offenders are located in real time through the electronic device attached to their ankle. Depending on the technology used, one can either track the exact location of tagged offenders (GPS tracking) or simply make sure they are present in a designated place, usually their home (Radio Frequency tracking)

${ }^{2}$ These U.S. estimates are from Roman et al. (2012) and Kyckelhahn (2011). Similar figures apply in France, with a daily cost of $10 €$ under EM and about $100 €$ in prison (DAP, 2013)
} 
annual inflow of 70,000 prisoners (DAP, 2015).

However, in comparison to the increasing use of EM worldwide, there is surprisingly little causal evidence on the effects of electronic monitoring in terms of recidivism. Most existing studies use observational data to estimate how recidivism rates differ between groups of ex-prisoners and EM offenders, controlling for a small set of observable characteristics $^{3}$. Unfortunately, these estimates are likely plagued by selection bias because judges typically try to allocate electronic monitoring to the "best" offenders (those with good reentry prospects and a low intrinsic risk of recidivism). In France for example, the decision to incarcerate or to grant EM to convicted offenders is highly discretionary and involves a preliminary social investigation and a hearing of eligible offenders: it is therefore very likely that judges' decisions rely not only on measured characteristics (like age or offense type), but also on a wide range of unobservable factors such as motivation, reentry prospects, or family support, which may themselves explain recidivism.

Only two existing papers deal with this selection bias convincingly, using quasiexperimental designs where similar offenders face dissimilar punishments (Di Tella and Schargrodsky (2013) in Argentina, and Marie (2015) in England and Wales). They both find evidence of substantial beneficial effects of EM compared to prison, but these findings may be specific to the settings studied. In particular, in both papers, all EM offenders spent time in jail, prison, or both (either a short time as in the case of pretrial detention in Argentina, or a longer period in the case of the main sentence in England and Wales) and later were placed under electronic monitoring. Therefore these examples actually combine incarceration and EM, while in our study, EM offenders are all sentenced to prison sentence but never enter prison (front-door EM). Moreover, Argentina differs a great deal from the U.S. and Europe in terms of prison conditions

\footnotetext{
${ }^{3}$ In France for example, such methods yield a gap of about 20 percentage points in favor of EM offenders after five years (Benaouda et al., 2010)
} 
(much harsher in Argentina), type of offenders considered for EM (all types in Argentina) and duration of supervision under EM (more than one year on average in Di Tella and Schargrodsky (2013), compared to less than six months in Marie (2015) and in France).

The main contribution of this paper is therefore to estimate the effect of fully serving a prison sentence under EM instead of incarceration on future criminal activity in a large European country, namely France. A second contribution is that we are able to investigate the mechanisms explaining our main result, using detailed data from the monitoring period (requirements to be met, breaches, control visits at home, etc.).

France provides a good case-study for the analysis of EM as it was among the earlyadopters of electronic surveillance in Europe, and is now a massive user. Moreover, the sequential introduction of EM in France represents a natural experiment: electronic surveillance was introduced on an experimental basis in four pilot courts in the early 2000s, and later became available in an increasing number of courts. We discuss this gradual rollout in detail and provide evidence that the endogenous selection of EM by courts is unlikely. We argue that the incremental implementation of EM generated sharp, exogenous discrepancies in eligibility for electronic monitoring among similar offenders, based on time and location. Finally, another reason for studying France is that EM is considered a proper alternative to incarceration in the Penal Code as judges can fully convert any short prison sentence to electronic monitoring before incarceration. Therefore, all EM recipients under study in this paper were sentenced to prison, but ended up serving their whole sentence at home under electronic monitoring. All these features of EM in France allow us to obtain quasi-experimental estimates of the effect of serving time at home under EM instead of in prison.

Our results show that simple comparisons highly overestimate the crime-prevention effect of electronic monitoring. The inclusion of a rich set of covariates reduces the gap in five-year recidivism from $14-15$ pp to $8-9$ percentage points. When we also 
control for selection based on unobservable characteristics using variation in access to EM as IV, the estimated beneficial effect of serving time at home under EM, instead of incarceration, falls to 6-7 percentage points. This effect remains significant statistically and economically, as it suggests a long-term reduction in recidivism by $9-11 \%$ thanks to the use of EM. We also find that this beneficial effect is greater on EM offenders who had prior prison convictions, received control visits at home from parole officers while under EM, and were required to work. We show that the estimated reduction in reoffending is not merely a function of short-term incapacitation at home but reveals more profound change (desistance from crime, with less recidivism and less serious new offenses), where both rehabilitation and deterrence play an active role.

The remainder of the paper is organized as follows. Section 1 reviews the existing literature on EM and recidivism. Section 2 explains how EM was introduced into the French institutional context, as well as the data we use in our estimates. Section 3 presents our empirical strategy and provides support for the main identification hypothesis. Section 4 presents the main results and investigates the presence of qualitative effects (on offense type, severity) and heterogeneity in treatment effects (by type of offender and intensity of supervision). Section 5 discusses the mechanisms driving our results and their current validity in France. Section 6 contains our conclusions.

\section{Related Literature}

In line with the seminal model by Becker (1968), there is now compelling evidence that prison sentences prevent crime not only by incapacitating criminals behind bars, but also by deterring potential offenders (Abrams, 2013). However, it is less clear whether the experience of incarceration also prevents recidivism among prisoners, or whether alternative punishments might be more effective.

The main argument against non-custodial sanctions is that such sentences are more 
lenient than prison. According to the theory of specific deterrence, the personal experience of lighter punishment (in the form of EM instead of incarceration, for example) makes the threat of future sentences less salient and less costly, thus promoting recidivism. Recent evidence of such effects is found in Hjalmarsson (2009) (who compares recidivism of young offenders sentenced to custodial or non-custodial sanctions) or Kuziemko (2013) (with length of incarceration as a measure of sentence severity) ${ }^{4}$.

However, this beneficial deterrent effect of prison may be weakened by the negative side-effects of incarceration. First of all, prisoners are exposed to many criminal peers behind bars; prison facilities allow criminals to learn from each other, build new networks and find new opportunities for crime. This view of prison as a "school of crime" is strongly supported by recent empirical research on peer-effects in Florida (Bayer et al., 2009), Denmark (Damm and Gorinas, 2013) and France (Ouss, 2011). Second, traditional prisons fail to promote social rehabilitation and labor-market integration of inmates, due to low access to education, human capital depletion, social exclusion and stigma after release (Aizer and Doyle, 2015; Mueller-Smith, 2014; Western et al., 2001). Current empirical evidence suggests that more open prisons, with less restrictive detention regimes and better access to work and rehabilitation programs, are more effective at preventing recidivism (Mastrobuoni and Terlizzese, 2014; Chen and Shapiro, 2007; Drago et al., 2009).

Overall, existing research suggests that while incarceration can induce more specific deterrence than non-custodial sanctions, it also disrupts social and labor-market ties and can eventually lead to hardened criminality. Conversely, electronic monitoring has many desirable features (e.g. it allows offenders to maintain family relationships and keep their jobs) but it may also foster feelings of impunity, producing a criminogenic effect overall.

\footnotetext{
${ }^{4}$ In Sweden, a country with very short average prison stays (1-2 months), Landers $\varnothing$ (2015) also finds that exogenous increases in prison time actually promote employment after release, an effect which appears to be driven by increased rehabilitation and better preparation for release.
} 
Until recently, empirical research did not offer convincing estimates of the net effect of EM (compared to incarceration) on recidivism, due to the potential for contamination by selection bias (see Aos et al. (2006) and Villettaz et al. (2006) for meta-analyses). Only two recent papers explore quasi-experimental designs whereby arbitrary rules or random events lead similar offenders to receive different punishments (EM or incarceration).

In Buenos Aires, Argentina, criminal cases are assigned randomly among judges depending on their work schedules. Di Tella and Schargrodsky (2013) report that local judges differ greatly in their use of EM; only one third of them (100/293) ever use EM in Buenos Aires during the period under study (for a total of 386 EM granted). Di Tella and Schargrodsky (2013) use these ideological differences as exogenous variations in the probability of EM treatment, and find a significant $50 \%$ drop in the probability of rearrest after EM compared to prison. While this paper is the first to provide compelling evidence of the crime-prevention effect of EM, the authors note that such a striking effect may well be specific to Argentina; in that country, prison conditions are particularly inhumane, with extensive overcrowding and little hope for rehabilitation. In addition, all EM beneficiaries were pre-trial defendants who had already served time in jail, and even in prison for most of them, before their release under EM. Finally, many EM offenders in Argentina were serious violent criminals and the average monitoring period was very long (more than one year). These features are specific to the Argentinian case and most countries have different approaches towards EM (selection of low-medium risk offenders, shorter supervision).

Marie (2015) is the first to provide quasi-experimental evidence of the beneficial effects of electronic monitoring in Europe. Using a Regression Discontinuity approach, the paper provides evidence of a substantial beneficial effect of EM in England and Wales, with $20 \%$ to $40 \%$ reductions in the probability of rearrest within two years. However, the program under study grants EM as an early-release device, not as a front-door substitute 
for incarceration, so it remains uncertain whether fully converting custodial sentences to electronic surveillance before incarceration prevents recidivism in the same way.

The implementation of EM in Denmark also offers quasi-experimental evidence from Europe, but existing studies focus on the effect of EM on social welfare dependence (Andersen and Andersen, 2014) or educational outcomes (Larsen, 2016), not future criminal activity.

In France, prior work on EM and recidivism is mainly exploratory. Benaouda et al. (2010) compare reconviction rates between EM offenders and ex-prisoners and find a lower recidivism rate for the former, but they do not go further and therefore do not avoid the selection bias issue. Another approach employed by Ouss (2013) in France is to explicitly acknowledge the presence of selection bias and test how much selection is actually needed in the data to make the estimated effect disappear (in practice, a fictitious covariate is added in the model). Using this simulation-based method, Ouss (2013) concludes that an unreasonable amount of selection bias is needed, and thus that EM and parole actually reduce recidivism in France. However, it seems unclear which level of selection bias is reasonable or not, especially in the context of highly discretionary decisions made by professional judges after individual interviews with eligible offenders. Moreover, the conclusions from such sensitivity analyses highly depend on the richness of available data and on the quality of the benchmark regression, in terms of precisely controlling the main differences between the offenders placed under EM and those who are not.

In the current article, we take a more direct approach to estimating the causal effect on recidivism of serving time at home under electronic monitoring, instead of incarceration. Specifically, our empirical strategy exploits the gradual introduction of EM across French courts in the early 2000s as a natural experiment. 


\section{Institutional Context and Data}

We propose to estimate the following equation:

$$
\operatorname{Recid}_{i}=\alpha+\beta E M_{i}+u_{i}
$$

In order to obtain an unbiased estimate of $\beta$, we need to take into account the eligibility criteria for EM and control for observable differences between treated and non-treated individuals. However, we also have to correct for the potential for selection by French judges based on unobservables, as we explain below.

\subsection{An experiment (2000-2001) followed by a gradual rollout}

On December 19 1997, after years of parliamentary debates ${ }^{5}$, Law no. 97-1159 introduced electronic monitoring in France as a substitute for incarceration. Legally, EM is not a criminal sentence but a way of serving a prison sentence either before or after incarceration. It entails a home curfew (generally during nights and weekends) but also specific obligations assigned by the judge, such as working or family care. Though the law was passed in 1997, it took several years to prepare for the introduction of EM in France $^{6}$, and the practical implementation of electronic surveillance only began in year 2000 as a pilot experiment (Kensey et al., 2003; Lévy and Pitoun, 2004).

The EM experiment took place in four courts, or Tribunaux de Grande Instance, between October 12000 and October 1 2001; these courts were located in Agen, Aixen-Provence, Grenoble and Lille. As explained by Lévy and Pitoun (2004), the choice of these four pilot locations was mainly motivated by whether the local judge(s) and prison wardens were sympathetic with the project, whether prison staff and judicial authorities worked well together locally, or whether the EM experiment would face resistance from

\footnotetext{
${ }^{5}$ Two Members of Parliament, Bonnemaison and Cabanel, wrote seminal reports on EM in 1983 and 1996 respectively. See Bonnemaison (1983) and Cabanel (1996).

${ }^{6}$ Between 1997 and 2000, some preliminary studies were conducted in order to prepare a review on existing knowledge. These studies concluded that an experimental phase was necessary, in order to test the equipment and the software provided by the different suppliers.
} 
local unions ${ }^{7}$. However, as we show in detail in Section 3.3, these four pilot courts did not seem to differ from the other French courts on important observable characteristics such as post-prison recidivism, prison overcrowding or local crime trends.

On January 1 2002, just after the end of the experimental phase, 143 EM had been granted to offenders from the four pilot courts, of which 120 had expired. Then, the French department of corrections decided to expand electronic monitoring to the whole country. Starting in January 2002, all French courts were allowed to grant EM to offenders meeting the legal criteria. Local judges had first to request EM devices from the central administration and could then grant tags to offenders.

The process was extended and in the end it proved to be geographically heterogeneous. Only one new court, located in Béziers (in the south of France), granted EM as a substitute for incarceration in January 2002. The first wave of adoption actually occurred between December 2002 and May 2003, with a dozen new courts participating (see the map in Figure 7 Appendix A). The EM rollout then intensified in the second half of 2003 (78 courts had granted at least one EM by December) and in early 2004 (112 courts by May) (Lévy and Pitoun, 2004). This process continued over the next few months, and all French courts eventually adopted electronic monitoring ${ }^{8}$. Today, EM is widely used in France, with more than 20,000 tags granted every year, and about 10,000 offenders under EM on any given day (DAP, 2015). As we detail in Section 3, we take the staggered introduction of EM across courts over time as an opportunity to estimate the causal effect of EM on recidivism.

\footnotetext{
${ }^{7}$ Lévy and Pitoun (2004) also note that Agen hosts the national school of prison administration (ENAP), and that MP Cabanel comes from Grenoble: this may also explain why those two locations were chosen.

${ }^{8}$ According to discussions with practitioners, part of the explanation for the delay in the introduction of EM across courts has to do with ideological resistance, since EM was quite a revolution in France in the early 2000s: it involved both a new technology, and a new philosophy on prison sentences (offenders initially sentenced to prison could now avoid incarceration altogether thanks to EM)
} 


\subsection{Selecting offenders for EM}

Depending on EM availability at the court level, the path towards electronic monitoring is highly selective; offenders first have to meet several eligibility criteria, and must also receive the approval of a judge after an individual hearing. This judge, known as the Juge d'Application des Peines ${ }^{9}$, has ample room for discretion. The eligibility criteria are explicitly listed in the Code de procédure pénale:

- Offenders are to be sentenced to a short prison stay of no more than one year, or the remainder of their current sentence should not exceed one year ${ }^{10}$. In practice, about $90 \%$ of EM devices in France are granted before incarceration to short sentence offenders (Kensey et al., 2003) ${ }^{11}$.

- Offenders are to have a place to stay equipped with a fixed-line telephone (to install the electronic device) $)^{12}$.

Every offender who meets these two criteria and who is left free at trial (no bench warrant) is eligible for front-door EM (in the empirical section below, we discard all individuals who do not meet these criteria). The offender's case is automatically examined in the following months by a second judge, the Juge d'Application des Peines, who decides whether EM should be granted or not as an alternative to incarceration. In order to make his decision, this judge requests that an investigation be made by parole officers (to make sure that the landlord, family and offender give their consent, and that EM is practically possible). He later meets the offender and his lawyer (if any) for a hearing, which lasts about 20 or 30 minutes. The judge usually asks offenders questions about the current offense, the victims, past convictions, and which activities

\footnotetext{
${ }^{9}$ The Juge d'Application des Peines is never the same person as the sentencing judge (who rules on convictions and sentencing). Juges d'Application des Peines are only in charge of issuing the prison sentence, with EM as a possible front-door alternative to incarceration.

${ }^{10}$ This length was extended in 2009 to two years, but remained equal to one year for recidivists. Our data, which are focused on the years 2000 to 2003, are not affected by this legal change.

${ }^{11}$ In this study, we focus on offenders who benefited from EM before incarceration to estimate the effect of electronic monitoring as a complete substitute for prison.

${ }^{12}$ Having a fixed-line telephone is no longer necessary for current devices, but this condition was important during the time-period of our data.
} 
the offender would or could pursue under EM (work, training, medical treatment), etc. These interviews can therefore reveal qualitative aspects of the offender's case, that are not reported in official criminal files. A few weeks after this interview, the offender is informed of the judge's decision.

As expected from this process, Kensey et al. (2003) show that many factors are taken into account: type of offense (driving and drug offenses are particularly frequent among EM offenders), length of criminal record (recidivists are less likely to receive EM), attitude towards the sentence, "maturity" or "psychological stability", etc. In fact, Kensey and Narcy (2008) show that offenders placed under EM between 2000 and 2006 are more similar to those convicted for non-custodial sentences (suspended prison sentence, probation) than to incarcerated offenders: for instance, $92 \%$ of EM offenders were French compared to $77 \%$ among inmates; $42 \%$ had a partner, compared to $23 \%$ for prisoners. Only $18 \%$ of those under EM were illiterate or had a very low educational level, and $72 \%$ were employed before conviction (as opposed to 50\% and $34 \%$ among inmates).

Overall, French judges seem to use a great amount of discretion in selecting offenders under electronic monitoring, among the large pool of eligible offenders. EM offenders tend to have better reentry prospects (in terms of family support, work history, criminal background, etc.) and are therefore less likely to reoffend in the first place. These observable differences stress the need to include a rich set of individual characteristics as control variables in Equation 1 above. Furthermore, we rely on a quasi-experimental design to correct for the plausibility of a selection based on unobervable characteristics as well, since $E M$ is likely to be endogenous. We argue that the incremental rollout of EM in France between 2000 and 2003 provides such a setting. 


\subsection{Data and Descriptive Statistics}

Datasets To investigate this issue, we merge two nationwide surveys conducted by the French Prison Administration. The first survey consists of a cohort sample of prisoners released in the year 2002, and the second is the population of the 580 first EM recipients in France (between 2000 and 2003).

The first database contains a sample of 8499 offenders released between June 12002 and December 31 2002. It was constructed using two sources of data, penal files and criminal records. Penal files are filled out by the prison facilities themselves, while offenders are serving their sentence. They contain basic sociodemographic data about convicts (gender, date of birth, self-declared employment and marital status, education, home city) but also some information about offenses (date, specific offense, sentence) and incarcerations (location, dates of entry and release, sentence reductions). Criminal records register offenders' sentences, both before and after the incarceration that led to the 2002 release, up to the year 2008.

This sample is not drawn at random from the general French prison population. Indeed, some categories were fully sampled, such as women, parolees or juveniles. To obtain estimates that are representative of the population of released prisoners, we follow Solon et al. (2015) and always include as regressors the variables used to stratify the sample.

The second database is the only existing study of recidivism among EM recipients in France. It contains individual data on the population of the first $580 \mathrm{EM}$ offenders, from the inception of electronic surveillance in France until March $2003^{13}$. This dataset collects socio-demographic data and criminal records up to 2008, allowing a follow-up period of more than five years.

Criminal records allow us to construct our main dependent variable, recidivism,

\footnotetext{
${ }^{13}$ For additional details, see Kensey et al. (2003).
} 
from the two datasets. We define recidivism as any reconviction, regardless of the type of new offenses and sentences ${ }^{14}$. On occasion, we also focus on new prison sentences (reincarceration) to pinpoint cases of serious reoffending. Recidivism is measured after five years, which is typical for studies in France but much longer than most foreign research. In order to pinpoint new offenses in the at-risk period, the clock starts on day of release for prisoners, and on first day under electronic monitoring for EM recipients ${ }^{15}$. In addition to reconvicted offenders, we consider as recidivists the $26 \mathrm{EM}$ recipients who were sent to prison during their supervisory period due to repeated incidents or a new offense. Neglecting those "failures" would skew the comparison in favor of EM.

Sample restrictions After merging the two samples, we obtain 9079 individuals. However, we make several sample restrictions to make the treated and control groups more comparable (see Appendix B for more details). First, out of the 580 EM offenders, $515(88 \%)$ were placed under EM as a complete alternative to incarceration (front-door EM) while the others obtained early release under EM during their prison stay. As we intend to study the effect on recidivism of being placed under EM instead of serving time in prison, we consider the former group as the treated (EM offenders), while dismissing the latter from the sample. Some observations are dropped in both groups since they are not usable (due to death or the absence of criminal record for example) or have missing or inconsistent values for important variables (such as sentence length). We also drop all prisoners who were not eligible for EM, either because their original sentence was over 12 months, because they didn't have a home address, or because they were incarcerated

\footnotetext{
${ }^{14}$ We acknowledge that the use of reconviction data is an imperfect measure of recidivism (some offenses are not detected and prosecuted), and does not provide complete data on rehabilitation. However, there is no data on ex-prisoners' rehabilitation or self-reported crime in France. Moreover, even though the absence of recidivism does not guarantee rehabilitation, we argue that rampant recidivism clearly suggests a failed reentry.

${ }^{15} \mathrm{An}$ alternative is to start the clock for EM recipients on the end date of surveillance; this would account for potential short-term incapacitation during home curfew under EM, but, conversely, it would overlook new offenses during surveillance. In robustness checks, we show that our estimates are not affected by the choice of starting time.
} 
before or on the day of conviction (pre-trial detention or bench warrant) ${ }^{16}$. Finally, we exclude from most regressions individuals whose follow-up period for new convictions is shorter than five years. All these restrictions reduce our study sample to 2827 offenders, of which 457 were sentenced to front-door EM while 2370 served time in prison.

Descriptive statistics Table 6 in Appendix B reports descriptive statistics with regard to sociodemographic data, judicial variables and recidivism, for the full study sample (Column 1) but also both for EM offenders (Col. 2) and non-EM offenders (Col. 3). Even after our sample restrictions, the two groups differ significantly in a wide range of areas (such as prior convictions and type of offense), as noted previously by Kensey et al. (2003). In terms of recidivism within five years, the two groups also differ dramatically; $66 \%$ of ex-prisoners are reconvicted compared to $46 \%$ of ex-EM offenders, yielding a gap of 20 percentage points (after correcting for the stratification of the prisoner sample). Figure 1 plots the evolution of recidivism rates over time: the recidivism gap between ex-prisoners (red) and EM recipients (blue) is substantial and quite stable over the entire follow-up period, and even more substantial when we focus on new prison sentences (25 pp after five years).

\section{Empirical Strategy and Specification}

\subsection{Exploring the gradual rollout of EM in France}

Our empirical strategy exploits the early stages of the gradual introduction of EM in France (2000-2003). As described in Section 2.1, EM was first tested as an experiment in only four courts, called Pilot courts, starting in October 2000. EM later became legally available to all French courts in January 2002, but most of them did not use EM

\footnotetext{
${ }^{16}$ Our view is that these prisoners are inherently different from EM offenders, as judges considered that their case required rapid incarceration. Conversely, the very fact that treated offenders were placed under EM at home demonstrates that judges didn't view them as too dangerous. This major difference leads us to consider as controls only prisoners who were incarcerated strictly after their final prison conviction.
} 
Figure 1: Recidivism over time

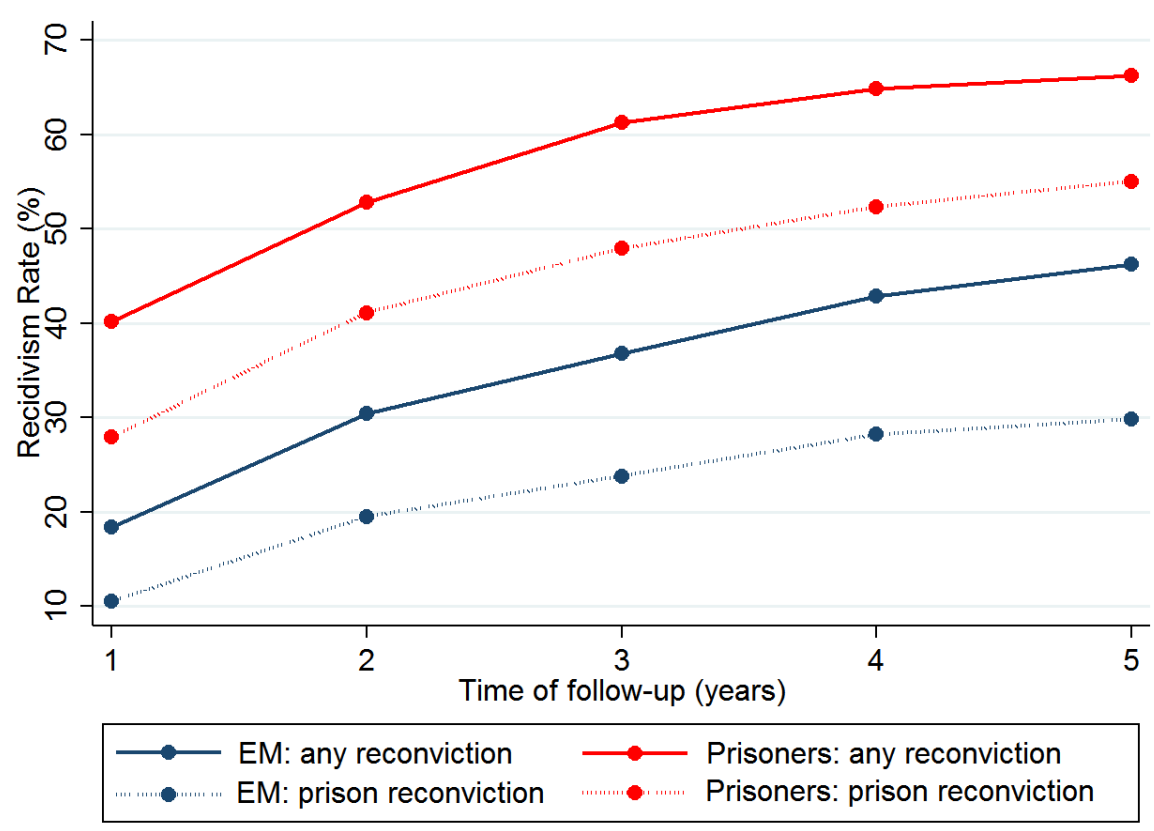

until much later. We can track very precisely the staggered implementation of EM in all French courts between 2000 and April 2003 thanks to thorough data collected by Kensey and Benaouda (2011) on the population of the first 580 offenders who were granted EM in France (as a front-door or back-door strategy). As an illustration, Figure 2 plots the cumulative number of EM granted in Pilot courts over the period. EM was adopted at a fairly constant rate in all four courts between 2000 and 2003.

Table 7 in Appendix C reports the total number of EM granted by March 2003 in the four Pilot courts and in the 13 next courts to implement EM (at least once) by this date. Those 13 courts are called early-adopters, whereas all the other French courts are labelled as late-adopters (they adopted EM later on and thus do not appear in our EM dataset).

Intuitively, this staggered implementation of electronic surveillance in France resembles a natural experiment under which similar offenders face differential access to EM depending on time and location: with all other factors remaining constant, offenders located in courts that were currently using EM had more chances of receiving EM than offenders located in courts that had not yet adopted EM. In addition to EM availabil- 
Figure 2: Number of EM granted in Pilot courts

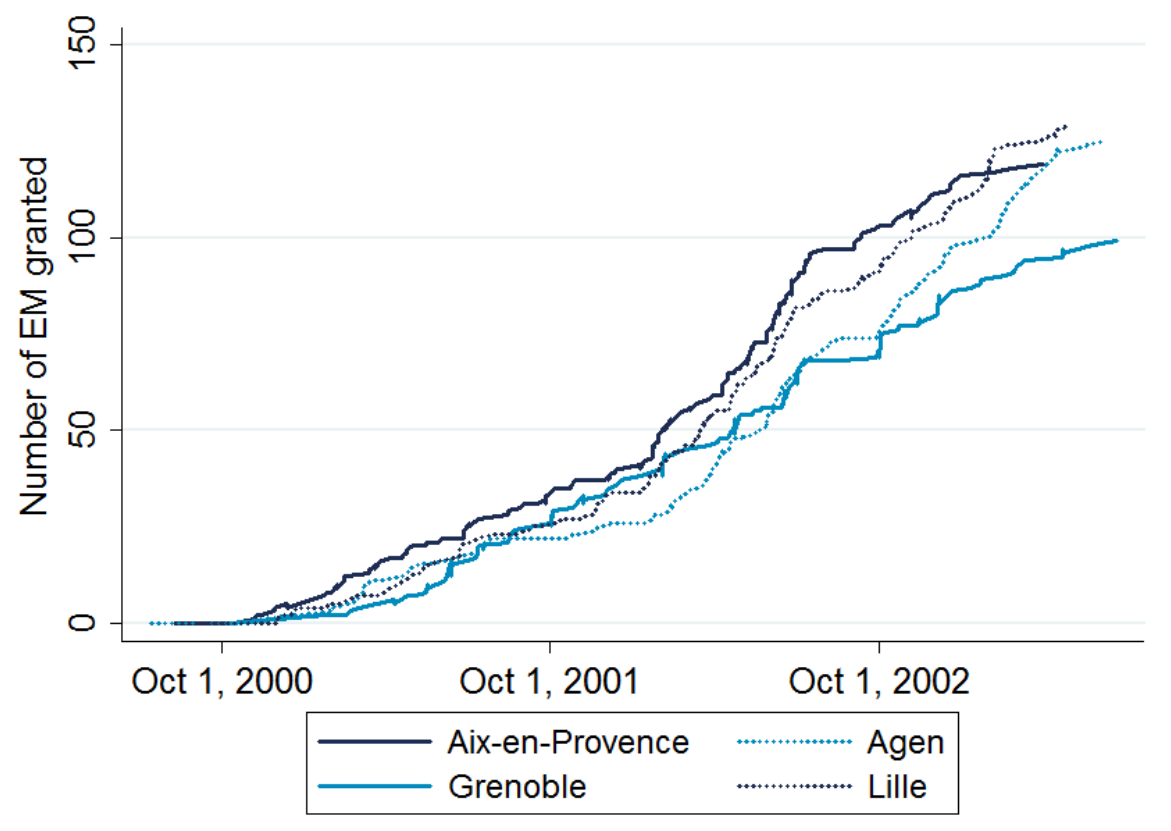

ity at the court level, we also measure the past intensity of EM use by the court (i.e. court $c$ often or rarely used EM before $i$ ) to utilize the fact that the magnitude of EM use changes over time and differs between pilot and early-adopter courts. These two instrumental variables are similar to those used by Di Tella and Schargrodsky (2013) in Argentina.

\subsection{Econometric Specification}

Formally, we consider a two-equation model where the probability of reoffending and the probability of receiving EM are estimated jointly:

$$
\begin{aligned}
& \operatorname{Recid}_{i, c}^{*}=\beta_{0}+\beta_{1} E M_{i}+\boldsymbol{X}_{i}^{\prime} \boldsymbol{\beta}+\epsilon_{i, c} \\
& \operatorname{EM}_{i, c}^{*}=\alpha_{0}+\alpha_{1} \text { CourtAlreadyUsedEM } M_{i, c}+\alpha_{2} \text { ShareEM }_{i, c}+\boldsymbol{X}_{i}^{\prime} \gamma+e_{i, c}
\end{aligned}
$$

Equation 2 resembles our naïve Equation 1 and simply estimates the effect of $E M$ on Recid, controlling for a vector of observable characteristics $\boldsymbol{X}$. Therefore, Equation 2 alone does not correct for the selection of EM recipients from unobservable character- 
istics.

To correct for the potential endogeneity of $\beta_{1}$, we estimate a recursive Bivariate Probit model of Equations 2 and 3 by Maximum Likelihood: such a model explicitly controls for the correlation between the two error terms (the unobservables), denoted $\rho$. As an alternative method, we also use Two Stage Least Squares (2SLS) with Eq. 3 as the first-stage.

The introduction of instrumental variables in Equation 3 provides the identification of $\beta_{1}$. The main instrument, CourtAlreadyUsedEM, is a dummy taking 1 if a court $c$ has previously granted EM before offender $i$ starts his own sentence in that court (and 0 otherwise). We also include a second instrument in places, called ShareEM: it computes the percentage of previous offenders in court $c$ who received EM before offender $i$ starts his own sentence in that court (only using in the denominator previous offenders who started their sentence while EM was legally available in their court). Note that this second instrument might be confusing as the denominator is calculated from our prison dataset, a sample that is representative at the national level ${ }^{17}$ but not necessarily at the court level. However, we expect ShareEM to provide a good proxy for the intensity of EM use by courts over time (accounting for court size). Importantly, the structure of the error term allows for intra-court correlation in all regressions.

The vector $\boldsymbol{X}$ is the same in both equations and includes a rich set of individual characteristics. First, we include in all regressions the variables used to stratify the prisoner sample to obtain a representative estimate of the effect of EM use on recidivism $^{18}$; this includes type of initial offense, gender, juvenile $($ age $<18)$, and early-release under parole. Thus we can measure how benefiting from EM affects the probability of reoffending in a representative sample of prisoners.

We also include sociodemographic variables that are presumably correlated with both

\footnotetext{
${ }^{17}$ When stratification is taken into account.

${ }^{18}$ As recently suggested by Solon et al. (2015). This is particularly important since the sample of prisoners overrepresents parolees, a positively selected group of prisoners with good reentry prospects.
} 
EM treatment and future crime: age and age squared, employment status, relationship status and parenthood.

We control precisely for criminal background using four variables: two dummies for prior convictions to prison or alternative sentences, and two continuous variables for the total number in each category.

We also add a dummy for other early release programs ${ }^{19}$ to account for the potential effects of early-release among prisoners. Finally, we include a linear trend for date of release to get rid of potential time trends in the risk of recidivism over time (due to changes in policing or economic conditions for example) between our two datasets ${ }^{20}$.

\subsection{Testing for the endogenous selection of EM by courts}

Our empirical strategy assumes that access to EM varied exogenously across courts and over time, i.e. courts' decisions to use EM early (and the extent of such use) was not related to court-level characteristics that may themselves affect recidivism. As we extensively control for a set of individual variables, our assumption of exogenous IV is conditional on $X$ so that our strategy should not be sensitive to compositional changes across courts over time (in terms of demographics or criminal background). However, if adopting EM was a reaction to high recidivism, rising crime rates or massive overcrowding in local prisons for example, this assumption would not hold true. To investigate this scenario of the endogenous selection of EM by courts, we collected additional data to check whether EM courts differed from late-adopters.

First, we consider whether recidivism rates were different between EM and nonEM courts before the introduction of electronic monitoring. To do so, we restrict the sample to prisoners who were incarcerated before EM became available in their court

\footnotetext{
${ }^{19}$ In addition to parole, prisoners can obtain early-release under semi-liberté and placement $\grave{a}$ l'extérieur (halfway-houses)

${ }^{20}$ Remember that prisoners are released in the second half of 2002, whereas EM offenders are released in the 2000-2003 period. In addition to the inclusion of a linear time variable, we later consider the potential for non-linear time trends in robustness checks (results are robust).
} 
(Oct. 12000 in pilot courts; Jan. 12002 in all other courts). We account for the resulting difference in average sentence length between pilot and non-pilot courts by including a second-degree polynomial of initial sentence length. Probit regressions of recidivism on the type of court (pilot, early-adopter, or late-adopter) are reported in Table 8 (Appendix D). There is no evidence that early adoption of EM was related to differences in the probability of recidivism, either in the raw data or after controlling for a rich set of individual characteristics (to make sure that comparisons are not skewed by differences in offenders' composition across courts); the estimated differences are both small in magnitude $(+2 /-3$ percentage points) and insignificant. Similarly, we look at recidivism in the late 1990s, using a previous cohort sample from the department of corrections (Kensey and Tournier, 2005). This dataset originates from a nation-wide representative study of 2207 ex-prisoners released in 1996-1997, whose reconvictions were followed until 2002. Again, raw and covariate-adjusted differences in recidivism are small and insignficant between pilot, early-adopter and late-adopter courts. Overall, these results do not support the scenario that courts which rapidly adopted EM (between 2000 and 2003) were different from other French courts in terms of recidivism. Therefore, our estimates are unlikely to be driven by local differences in recidivism.

Second, we consider local crime rates. We could expect that courts decided to adopt EM to manage a surge in local crime, threatening our empirical strategy (since local crime may correlate with our instruments and recidivism). To test this hypothesis, we gather monthly département-level data ${ }^{21}$ (the French Interior Ministry doesn't provide crime statistics at the court level). We compare crime levels and crime trends in départements with a pilot or early-adopter court, and other départements where no court adopted EM rapidly (late-adopters). As we see in Figure 3, in levels, pilot and early-adopters tend to display substantially higher crime rates during the 1996-2001 pe-

\footnotetext{
${ }^{21}$ Départements are small administrative regions in France, like counties. France contains a total of 101 départements and the average number of High Courts per département is two.
} 


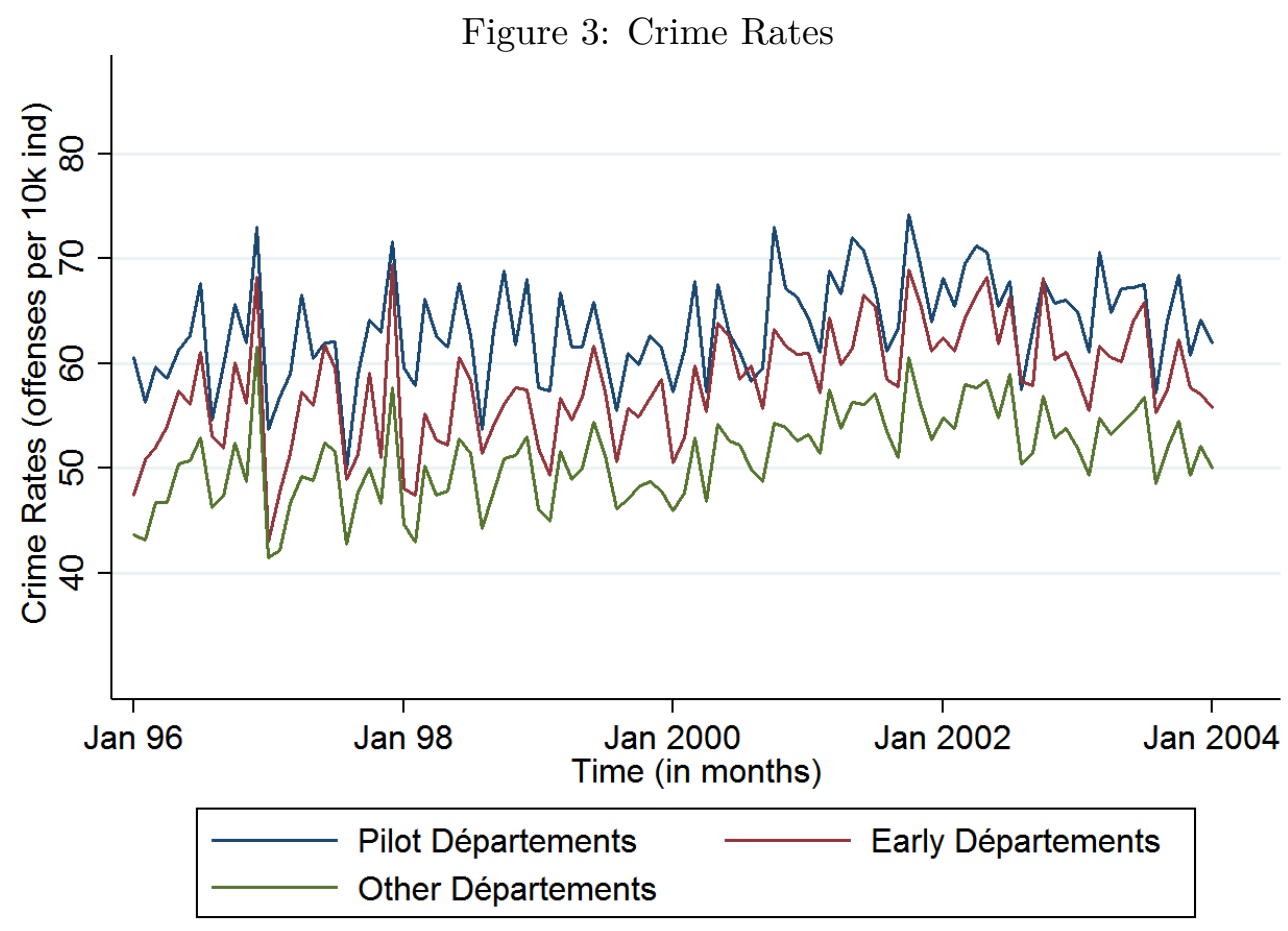

riod (levels are expressed in number of reported offenses per 10,000 inhabitants). This is probably due to the fact that pilot and early-adopter départements include densely populated areas (Marseille, Lille, Paris, etc.) which have higher levels of crime. However, crime trends are remarkably parallel in all three types of départements throughout the period. The same parallel trends are also observed when we split crime rates between property crime and violent crime (Figure 9 in Appendix D). Hence, the gradual adoption of EM across courts didn't seem to be a reaction to different trends in local crime rates.

Third, we consider prison overcrowding. Rising population/capacity ratios may have pushed some courts into electronic monitoring, which may independently affect recidivism. To test this hypothesis, we collect overcrowding rates in all prison facilities on January 1st of each year (1996, 1999, 2000, 2001, 2002) and construct weighted average rates for each type of court, based on the flow of offenders convicted in court $c$ and incarcerated in prison $p$. Figure 8 (Appendix D) shows how these overcrowding rates vary over time for the three types of courts: overcrowding tends be somewhat greater in pilot and early-adopter courts, but differences are small (less than 10 percentage points) and 
insignificant. Similarly, when we focus on short-term prisons (Maisons d'Arrêt), differences remain modest. Based on the small existing elasticities of recidivism with respect to prison overcrowding (Drago et al., 2011), we do not expect such small differences to affect our effects of EM use. In addition, note that overcrowding in early-adopter courts was very close to late-adopter courts on January 2002 (when EM was legalized in all courts), suggesting that courts which adopted EM rapidly did not face any particular problem of overcrowding compared to other French courts.

Finally, a minor concern is that some offenders may have strategically moved to EM courts after the introduction of the device to avoid incarceration in case of arrest. Hence unobservable traits could correlate with both our instruments for access to EM and recidivism. This scenario seems highly unlikely in practice because EM was a small program everywhere during the study period (so chances of being placed under EM were low anyway); second, $98 \%$ of those who received EM lived in the département where they were tried. Therefore, we can safely ignore this concern of strategic choice of crime location.

\section{Results}

\subsection{Benchmark estimates}

We first report in Table 1 naïve estimates of Equation 2 using probit and linear probability models. They serve as a benchmark since they treat the use of EM as exogenous, and therefore do not correct for potential selection bias. We focus on the more conservative Probit estimates, but the OLS results are very similar.

The specification in Column 1 doesn't control for any individual characteristic but simply accounts for the stratification of the prisoner sample. The estimate suggests that EM offenders are 15 percentage points less likely to be reconvicted in the next five years than those released from prison. This difference is both great in magnitude and 
Table 1: Electronic Monitoring and Recidivism

\begin{tabular}{|c|c|c|c|}
\hline & $\begin{array}{c}\bar{Y}=\underset{(1)}{\text { Any } \mathrm{R}} \\
\text { (1) }\end{array}$ & $\begin{array}{c}\text { econviction } \\
(2)\end{array}$ & $\begin{array}{l}\text { e Next } 5 \text { Years } \\
(3)\end{array}$ \\
\hline \multicolumn{4}{|l|}{ Probit Model } \\
\hline Electronic Monitoring & $\begin{array}{c}-0.1523^{* * *} \\
(0.0409)\end{array}$ & $\begin{array}{c}-0.1276^{* * *} \\
(0.0320)\end{array}$ & $\begin{array}{c}-0.0832^{* *} \\
(0.0286)\end{array}$ \\
\hline Pseudo $R^{2}$ & 0.17 & 0.22 & 0.27 \\
\hline \multicolumn{4}{|l|}{ Linear Prob. Model } \\
\hline Electronic Monitoring & $\begin{array}{c}-0.1614^{* * *} \\
(0.0440)\end{array}$ & $\begin{array}{c}-0.1344^{* * *} \\
(0.0351)\end{array}$ & $\begin{array}{c}-0.0954^{* *} \\
(0.0318)\end{array}$ \\
\hline$A d j . R^{2}$ & 0.21 & 0.26 & 0.31 \\
\hline Demographics & & $\mathrm{x}$ & $\mathrm{x}$ \\
\hline Past convictions & & & $\mathrm{x}$ \\
\hline $\mathrm{N}$ & 2827 & 2827 & 2827 \\
\hline
\end{tabular}

Robust standard errors in parentheses, clustered at court level. ${ }^{+} p<0.1 ;{ }^{*} p<0.05 ;{ }^{* *} p<0.01$ $;^{* * *} p<0.001$. All regressions control for the variables used for stratified sampling. Probits report Average Marginal Effects.

highly significant. To account for the fact that prisoners differ from EM recipients in many observable areas (see Table 6 in Appendix), we control in Col. 2 for the set of demographic variables: the difference in recidivism drops to 13 pp. Finally, controlling precisely for past convictions further reduces the estimated gap in recidivism to $8 \mathrm{pp}$.

Overall, the inclusion of a large set of covariates decreases the estimated gap in recidivism by more than $45 \%$, from about $15 \mathrm{pp}$ to $8 \mathrm{pp}$. This pattern supports the idea of a positive selection based on observables by French judges in assigning EM: i.e. offenders who were granted EM displayed relatively good prospects (in terms of employment, family support, criminal background, etc.) and low risk of recidivism. However, even after controlling for this large set of characteristics, the estimated difference in recidivism remains largely and significantly in favor of EM recipients compared to incarcerated offenders. 


\subsection{Causal estimates by IV}

In order to account for potential selection based on unobervables as well, we turn to our two-equation model with instrumental variables. Column 1 reports our benchmark probit estimate $(-8.3 \mathrm{pp})$ when the EM treatment is considered exogenous. In Col. 2 and 3, we run our recursive bivariate probit model by maximum likelihood, with one instrument or both instruments together.

First, our instrumental variables behave as expected: the estimates suggest that previous use of EM in a court significantly predicts one's chances of obtaining electronic monitoring. As expected with selection based on unobservables, the correlation coefficient $\rho$ is negative and the estimated average marginal effect of EM decreases. However, this estimate of $\beta_{1}$ is still great and significant, and suggests that serving time at home instead of in prison reduces recidivism after five years by seven percentage points on average.

In Col. 5 and 6 , we estimate the same model by 2SLS; the results show similar evidence of selection bias in benchmark regressions. The estimated causal effect of EM is somewhat slighter and less precise than after bivariate probit estimation, close to six percentage points. Hansen's test of overidentification shows no evidence of violation of the exogeneity condition, which further supports the credibility of our results.

Overall, these causal estimates tend to be somewhat lower than the benchmark, naïve estimates (though differences are not statistically significant). This pattern, and the negative sign of $\rho$, support the idea that judges wisely selected EM offenders based on both observable and unobservable characteristics. However, even after controlling for this selection process, a large and significant gap of six to seven percentage points in the risk of recidivism remains. We attribute it to the average treatment effect on the treated of serving time at home under electronic monitoring instead of in prison. Given the $65 \%$ recidivism rate in the representative sample, our results suggest that the use of 
EM reduces the probability of recidivism by nine to eleven percent after five years. 
Table 2: Electronic Monitoring and Recidivism

\begin{tabular}{|c|c|c|c|c|c|c|}
\hline & $\begin{array}{l}\text { Probit } \\
\text { (1) }\end{array}$ & $\begin{array}{c}\text { Bivariate Probit } \\
\text { with } 1 \text { IV } \\
\text { (2) }\end{array}$ & $\begin{array}{c}\text { Bivariate Probit } \\
\text { with } 2 \text { IV } \\
(3)\end{array}$ & $\begin{array}{l}\text { OLS } \\
(4)\end{array}$ & $\begin{array}{c}\text { 2SLS } \\
\text { with } 1 \mathrm{IV} \\
\quad(5)\end{array}$ & $\begin{array}{c}\text { 2SLS } \\
\text { with } 2 \text { IV } \\
\text { (6) }\end{array}$ \\
\hline$Y_{1}=$ Recidivism & & & & & & \\
\hline ElectronicMonitoring & $\begin{array}{c}-0.0832^{* *} \\
(0.0286)\end{array}$ & $\begin{array}{l}-0.0705^{*} \\
(0.0323)\end{array}$ & $\begin{array}{l}-0.0711^{*} \\
(0.0341)\end{array}$ & $\begin{array}{c}-0.0954^{* *} \\
(0.0318)\end{array}$ & $\begin{array}{r}-0.0553^{+} \\
(0.0316)\end{array}$ & $\begin{array}{r}-0.0571^{+} \\
(0.0343) \\
\end{array}$ \\
\hline$Y_{2}=$ Electronic Monitoring & & & & & & \\
\hline CourtAlreadyUsedEM & & $\begin{array}{c}0.1294^{* * *} \\
(0.0078)\end{array}$ & $\begin{array}{c}0.0956^{* * *} \\
(0.0145)\end{array}$ & & $\begin{array}{c}0.6365^{* * *} \\
(0.0481)\end{array}$ & $\begin{array}{c}0.3813^{* * *} \\
(0.1042)\end{array}$ \\
\hline ShareEM & & & $\begin{array}{l}0.0582^{*} \\
(0.0254)\end{array}$ & & & $\begin{array}{c}0.4986 * * \\
(0.1731)\end{array}$ \\
\hline Demographics & $\mathrm{x}$ & $\mathrm{x}$ & $\mathrm{x}$ & $\mathrm{x}$ & $\mathrm{x}$ & $\mathrm{x}$ \\
\hline Past convictions & $\mathrm{x}$ & $\mathrm{x}$ & $\mathrm{x}$ & $\mathrm{x}$ & $\mathrm{x}$ & $\mathrm{x}$ \\
\hline$\rho$ & & $-0.121(0.103)$ & $-0.126(0.113)$ & & & \\
\hline $\begin{array}{l}\text { Hansen J test of exogeneity: p-value } \\
\mathrm{N}\end{array}$ & 2827 & 2827 & 2754 & 2827 & 2827 & $\begin{array}{l}0.706 \\
2754\end{array}$ \\
\hline
\end{tabular}

Robust standard errors in parentheses, clustered at court level. ${ }^{+} p<0.1 ;{ }^{*} p<0.05 ;{ }^{* *} p<0.01 ;{ }^{* * *} p<0.001$. All regressions control for the variables used to stratify the prisoner sample. Probits and Biprobits report Average Marginal Effects obtained by Maximum Likelihood. 


\subsection{Robustness Checks}

We run a series of robustness checks in Table 9 (Appendix E). First, we limit the potential for unobserved heterogeneity among courts and socioeconomic contexts. Thus, we focus on neighboring courts within a radius of 100 kilometers from each EM court. This restriction reduces the sample by one third, but still yields significant negative estimates for $E M$, suggesting that our results are not driven by unobserved contextual differences.

A second concern is that local crime rates may both explain recidivism and the decision by the courts to implement EM. Though Figure 3 tends to reject it graphically, we further consider this hypothesis by including in our regressions two additional covariates: local crime rates in one département in the starting month of the sentence, and the percentage change in local crime in the past two years. The estimates remain significantly in favor of EM (-7.5 percentage points).

Another concern is that our dataset merges two samples from different time periods: ex-inmates are all drawn from a cohort of prisoners released between June 1 and December 31 2002, whereas the EM group contains all those who were discharged from electronic surveillance from the beginning of the program (end of 2000) to March 2003. Therefore, our results could be sensitive to non-linear time trends in the risk of recidivism, for example due to temporal breaks in police forces or economic conditions. To deal with such temporal shifts, we drop all EM offenders who were discharged long before or long after the second half of 2002. To retain a sufficient number of EM beneficiaries, we keep those who were discharged between March 12002 and March 312003. Again, the estimate remains similar so temporal breaks in the risk of recidivism are not a concern.

Fourth, we use an alternative starting date for the measure of recidivism: up to now, we have computed recidivism as any new conviction in the five years following 
date of release (for prisoners) or the starting date of electronic surveillance (for EM offenders) since they are at risk of reoffending even during their monitoring period. However, one may argue that EM offenders are somewhat incapacitated at home while under electronic surveillance, so that the at-risk period actually starts at the end of the electronic monitoring. We use this alternative starting date to compute recidivism, and find similar results again.

Fifth, we rely only on the "largest" courts representing a total number of convicted offenders above the median (median number of offenders is 20 in our original dataset), as court size is important in the construction of our second instrument. We again obtain similar results.

Sixth, we turn to a different set of instruments, using only cross-court differences in EM use. Specifically, we use two dummies as IV, Pilot and Early-adopter, which pinpoint whether offender $i$ was located in a court that ever used EM during the full period. This approach doesn't use time differences in access to EM but leads to similar conclusions.

Finally, another approach is to follow the evolution of aggregate recidivism rates over time as courts adopt EM. If electronic monitoring is indeed effective, court-level average recidivism rates should decline as courts grant EM to offenders who would otherwise be incarcerated. To explore such changes in recidivism between cohorts of offenders convicted before and after the adoption of EM in their court, we first need to control for the fact that these successive cohorts of convicts differ systematically in initial prison sentence length (a strong predictor of recidivism); thus we regress recidivism in pilot and early-adopter courts on a polynomial of sentence length, and use the residuals as a measure of the propensity to reoffend which is clean of (i.e. unexplained by) systematic differences in sentence length. Figure 11 (Appendix E) plots these residuals for different cohorts of convicts who start their sentence in the twelve quarters before or after the 
introduction of EM in their court ( 0 corresponds to the quarter of introduction of EM in one's court). As expected, the graphical evidence shows a drop in recidivism after courts adopt EM, which is consistent with a crime-prevention effect of electronic monitoring.

\subsection{Why/When is EM effective?}

We now explore the heterogeneity of treatment effects. To do so, we run separate regressions of the same bivariate probit model (as in Table 2) on subsamples of EM offenders, based on possibly relevant mediating factors. The EM effect estimates for each subgroup are displayed in Table 3.

Regarding demographic characteristics, we do not find much evidence of heterogeneity among EM offenders. Estimated treatment effects are quite independent of the age of EM offenders (relative to the median, 30 years old) and prior employment status. However, the beneficial effect of EM seems greater among parents and, more importantly, among offenders who had already been sentenced to prison before (-12 percentage points). We view this last result as evidence that EM is mostly effective on offenders who know what is at stake should they reoffend (most probably incarceration) and do not view EM as a lenient, non-deterrent sanction but as a second chance. Conversely, granting EM to offenders who have never experienced prison might create deleterious feelings of impunity, thus reducing the effectiveness of electronic monitoring.

The type and intensity of supervision under EM also seem to matter. First, electronic monitoring is very effective at reducing recidivism among those who have received at least one visit from parole officers during curfew hours, to check that they have truly followed the rules (-9 pp), while it is not among the others. One may suspect endogeneity in the choice of visiting certain offenders and not others, but note that if the most crimeprone offenders are targeted for control visits, this bias would presumably attenuate, not exacerbate, the estimated effect of visits on recidivism ${ }^{22}$. The striking difference

\footnotetext{
${ }^{22}$ Moreover, it appears that the probability of a control visit mainly varies among courts, not among
} 
Table 3: Heterogeneity of effects by profile and supervision

\begin{tabular}{lccccc}
\hline \hline \multirow{2}{c}{ Profile } & Yes & No & Supervision & Yes & No \\
\hline \multirow{4}{*}{ Younger than 30} & $-0.0811^{*}$ & $-0.0897^{*}$ & & & \\
& $(0.0342)$ & $(0.0440)$ & Control visit at home & $-0.0926^{* * *}$ & -0.0218 \\
Has children & $-0.1082^{*}$ & $-0.0526^{+}$ & & $(0.0229)$ & $(0.0371)$ \\
& $(0.0471)$ & $(0.0277)$ & EM length $>$ median & $-0.0824^{+}$ & -0.0543 \\
Employed & $-0.0768^{+}$ & $-0.0944^{+}$ & & $(0.0440)$ & $(0.0378)$ \\
\multirow{4}{*}{ Prior incarceration } & $(0.0393)$ & $(0.0521)$ & Obligation: work & $-0.0816^{*}$ & 0.0043 \\
& $-0.1181^{*}$ & $-0.0559^{+}$ & Violation during EM & $-0.0332)$ & $(0.0591)$ \\
& $(0.0511)$ & $(0.0330)$ & & $(0.0403)$ & $-0.1077^{* *}$ \\
& & & & & \\
\end{tabular}

Robust standard errors in parentheses, clustered at court level. ${ }^{+} p<0.1 ;{ }^{*} p<0.05 ;{ }^{* *} p<0.01$ ; ${ }^{* * *} p<0.001$. The table reports Average Marginal Effects of bivariate probit models (ML). All regressions include the full set of control variables.

in outcomes suggests that control visits act as a strong deterrent, which is in line with qualitative interviews with EM offenders in England (Hucklesby, 2009).

Our results also suggest that EM is more effective with offenders who were supervised longer (above the median length of two months), and who were required to work while under surveillance (-8 pp), controlling for prior employment status. As expected, we also find that EM fails to prevent recidivism among offenders who violated the rules while under surveillance (for example coming home late or leaving home during curfew hours).

We also investigate whether EM affects the seriousness of new offenses, using as proxies the type of new sentence (custodial or not) and the total length of new prison sentences accumulated over the entire five-year follow-up period ${ }^{23}$. The estimated marginal effects are reported in Table 4.

Estimates are substantial and suggest that EM reduces the probability of receiving a new prison conviction after five years by eight percentage points (18\%). When focusing offenders within courts : for example, $97 \%$ of EM offenders were visited in Aix-en-Provence, compared to only $10 \%$ in Agen. We take this as evidence that control visits were not endogenous case-by-case decisions, but reflected different local practices (as confirmed by Kensey et al. (2003)).

${ }^{23}$ Alternative sentences are coded as zero (censored) while the few life sentences are coded as 30 years (the maximum in the sample) 
Table 4: Seriousness of new crime(s) over the Next 5 Years

Any New Prison Sentence Total Length of New Prison Sent.

$\begin{array}{ccccc}\text { ElectronicMonitoring } & -0.0823^{* *} & -0.0973^{* * *} & -8.7884^{* *} & -8.9771^{* * *} \\ & (0.0320) & (0.0291) & (3.0985) & (2.2792)\end{array}$

\begin{tabular}{lcccc}
\hline Conditional on Recid & No & Yes & No & Yes \\
$\mathrm{N}$ & 2768 & 1583 & 2827 & 1635 \\
Sample Average & $45.7 \%$ & $73.5 \%$ & $19.46 \mathrm{mos}$ & $19.88 \mathrm{mos}$ \\
Estimated \% EM effect & -18 & -13 & -45 & -45 \\
\hline \hline
\end{tabular}

Robust standard errors in parentheses, clustered at court level. ${ }^{+} p<0.1 ;{ }^{*} p<0.05 ;{ }^{* *} p<0.01$; ${ }^{* * *} p<0.001$. Prison conviction estimates are obtained by bivariate probit. Prison sentence length estimates are obtained by jointly estimating a Tobit and a Probit on the sample of reoffenders. All regressions include the full set of control variables and correct for endeogeneity of EM using the same instruments.

on reoffenders only, the substantial beneficial effect of EM remains, with an estimated $13 \%$ reduction in prison sentences for recidivism. The same pattern emerges for total length of future imprisonment (modelled as a Tobit censored in zero for those who are never resentenced to prison): serving time at home under EM reduces by half the expected prison time that reoffenders accumulate over the follow-up period (nine months over an average of 20 months).

Our severity estimates thus suggest that EM offenders commit less serious crimes than ex-prisoners in the next five years, conditional on recidivism. This interpretation is in line with the literature on hardening criminality inside prison (Abrams, 2011) ${ }^{24}$.

\section{Discussion}

\subsection{Incapacitation, deterrence, or genuine long-term change?}

While under electronic monitoring, offenders are compelled to respect strict home curfews for long hours, with permission to leave only for work or other rehabilitative activities. One may therefore suspect that the estimated crime-prevention effect of EM is

\footnotetext{
${ }^{24}$ We also consider whether EM affects certain types of new offenses more than others. The estimates, presented in Table 10 in Appendix E, are imprecise and inconclusive.
} 
Table 5: Causal effects in different time windows

\begin{tabular}{|c|c|c|c|c|c|c|c|}
\hline & Q1 & Q2 & Y1 & $\mathrm{Y} 2$ & Y3 & $\mathrm{Y} 4$ & Y5 \\
\hline ElectronicMonit. & $\begin{array}{c}-0.0290 \\
(0.0269)\end{array}$ & $\begin{array}{r}-0.0578^{+} \\
(0.0307)\end{array}$ & $\begin{array}{c}-0.0933^{* * *} \\
(0.0263)\end{array}$ & $\begin{array}{c}-0.0848^{* *} \\
(0.0308)\end{array}$ & $\begin{array}{c}-0.1148^{* * *} \\
(0.0346)\end{array}$ & $\begin{array}{c}-0.0906^{* *} \\
(0.0313)\end{array}$ & $\begin{array}{c}-0.0711^{*} \\
(0.0341)\end{array}$ \\
\hline $\mathrm{N}$ & 3001 & 3001 & 3001 & 3001 & 3001 & 3001 & 2827 \\
\hline Recidivism Rate & $16.6 \%$ & $27.5 \%$ & $39.3 \%$ & $51.9 \%$ & $60.3 \%$ & $63.9 \%$ & $65.4 \%$ \\
\hline EM effect in \% & $(-17.5)$ & -21.0 & -23.7 & -16.3 & -19.0 & -14.2 & -10.9 \\
\hline
\end{tabular}

Robust standard errors in parentheses, clustered at court level. ${ }^{+} p<0.1 ;{ }^{*} p<0.05 ;{ }^{* *} p<0.01$

$;{ }^{* * *} p<0.001$. The table reports Average Marginal Effects of bivariate probit models (ML). All regressions use the same two instruments and the full set of control variables.

explained primarily by incapacitation at home. However, we dismiss this view for several reasons: first, the average period under electronic monitoring is only 73 days (about half of EM offenders spend no more than two months, and 95\% less than six months) so it seems unlikely that such short-term incapacitation may explain the substantial effects observed five years later. Second, we obtain very similar estimates when we start the five year clock after the end of the monitoring period (Table 9), which eliminates the short-term incapacitation-at-home effect. Third, the percent reduction in recidivism thanks to EM is not particularly great in the beginning (while under home curfew), but actually remains quite stable in the medium term (one to three years). To see this time pattern, we estimate the effect of EM on recidivism at different time periods: after only one quarter, one half year, and then each year up to the fifth year after release. The results in Table 5 show that the percentage reduction in recidivism is similar in the first quarter $(-17.5 \%)$ and after three years $(-19 \%)$. This pattern provides further evidence that the crime-prevention effect of EM is not driven by short-term incapacitation under home curfew: its impact remains similarly strong several years after the end of supervision.

Overall, our interpretation is that the beneficial effect of electronic monitoring on long-term recidivism derives from a mix of rehabilitation and deterrence. Indeed, our 
estimates in Table 3 suggest that the obligation to work while under EM helps prevent recidivism, probably through better attachment to the labor market and increased opportunity cost of crime. Also note that home curfew implies spending more time with family, and conversely less time outside exposed to criminal peers and opportunities. In addition to opportunity cost, such changes in social ties may foster change in preferences and attitudes, promoting desistance from crime (Hucklesby, 2009). Second, our results show that EM is most effective on offenders who have already been to prison before; this may suggest that receiving EM is not perceived as a lenient punishment by former prisoners, but more as a second chance and an opportunity to be seized: therefore, reduced deterrence (namely the impunity effect) may not be a concern for ex-prisoners, but only for inexperienced offenders who have never been in prison. Finally, we find that EM has much more impact when it is accompanied by control visits at the home of the offender. This last finding suggests that visits make the probability of detection more salient in the minds of offenders (upward updating of $p$ in the beckerian tradeoff), and that this effect lasts surprisingly much longer than simply during the monitoring period. All in all, we take this as evidence that short-term punishments in the community such as EM can have substantial, long-term effects on criminal behavior, provided that they include ingredients of both rehabilitation and deterrence.

\subsection{Current validity: diminishing returns and changes in supervision?}

Our results are obtained from the early stages of implementation of EM in France (from October 2000 to March 2003), a period when EM was a nascent alternative to incarceration, used in only a few hundred cases annually. As Figure 4 shows, the flow of offenders into EM rapidly increased after 2003, with about 6,000 EM delivered in 2006 for example. Today, it is estimated that about 20,000 offenders sentenced to prison avoid incarceration each year thanks to electronic monitoring. This substantial change 
Figure 4: The widespread development of EM in France

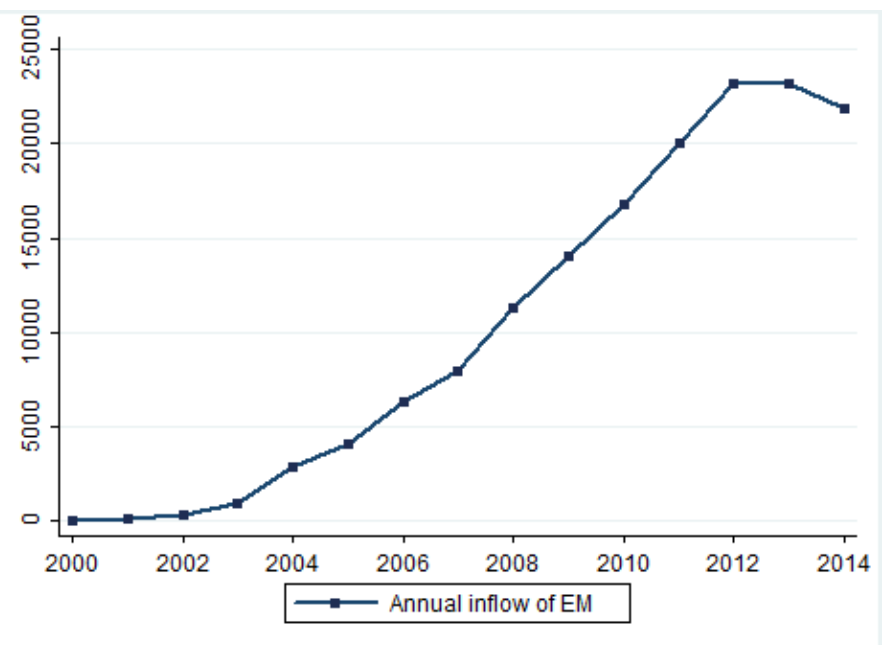

may have widespread implications for the current validity of our findings.

First, the marginal effectiveness of EM on recidivism may be decreasing if judges first target the best candidates for EM, i.e. offenders who would benefit the most from being placed under EM instead of prison (in terms of crime reduction). Using our limited data on the first 580 EM recipients, we can offer only suggestive evidence on this hypothesis of diminishing returns. To do so, we separate EM offenders who were among the first to obtain EM in their court, and offenders who were placed under EM later on. We fix the cutoff value at $50 \mathrm{EM}$ devices in a court to obtain two groups of the same size (with about 230 EM offenders each). We then run our bivariate probit model for both groups separately. The estimates in Table 11 (Appendix E) do not provide any evidence of marginally decreasing returns to EM: the estimated effect of EM on recidivism is very similar among offenders who were among the first to obtain EM (-6.1 pp) and later recipients $(-6.7 \mathrm{pp})$. Note that the correlation coefficients $\rho$ (zero in the first group, and significantly negative in the second group) suggest that judges were better at selecting EM recipients based on unobservable characteristics after a while (here, after 50 EM were delivered). However, this better selection of EM offenders over time did not lead to any sizable change in treatment effects in our data, suggesting that EM can be effective on a wide range of offenders. 
To further explore changes in the selection of EM offenders over time (and the potential implications for EM effects), we utilize more recent data collected by the French Prison Administration (Kensey and Narcy, 2008) on a large representative sample of about 2,000 EM offenders, from 2003 to 2006 (covering about $20 \%$ of all EM over the period). Figure 5 reports the changes in the main observable characteristics of EM offenders between 2000 and $2006^{25}$. Overall, there is little change in the profile of EM offenders, except for the increase in the portion of DUI offenses. This relative stability suggests that the process of selecting EM offenders remained similar between 2000 and 2006.

Figure 5: Observable characteristics of EM offenders
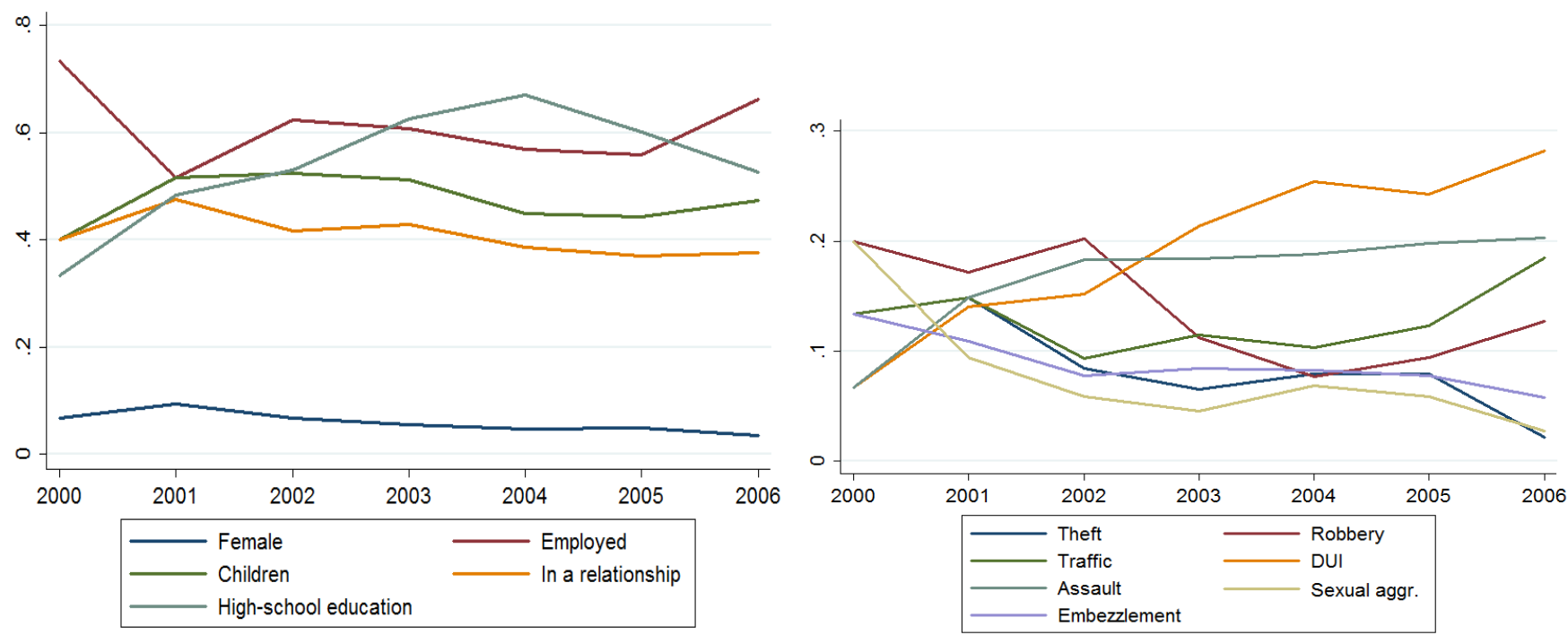

In terms of supervision however, the widespread development of EM in France had major consequences. Figure 6 shows the evolution of control visits at home (blue bars): from 2000 to 2002, about two thirds of EM offenders received at least one control visit from parole officers during their monitoring period. After 2003, these controls declined dramatically and almost disappeared in $2006^{26}$. Similarly, the median duration of EM sharply decreased over time, from about 80 days in 2000 to less than 50 days in 2006 .

\footnotetext{
${ }^{25}$ Unfortunaly the data doesn't include recidivism or past incarceration (which we find an important mediator in the effectiveness of EM).

${ }^{26}$ Correspondance with several practicioners suggests that such control visits are very rare today as well. But unfortunately, we do not have more recent data to support this trend.
} 
This pattern suggests that the widespread development of EM in France coincided with a sharp decrease in the supervision of EM offenders by parole officers. On the other hand, there is no major change in the occurence of incidents (about $40 \%$ of cases throughout the period), control visits after an incident (less than 10\%), or obligation to work (around $80 \%)$.

Overall, we view the dramatic fall in control visits and in the length of supervision as a threat to the current validity of our findings: indeed, our estimates in Table 3 suggest that EM was mainly effective in reducing five year recidivism among offenders who received control visits, and who were monitored for longer periods, while it had a lesser impact on the others.

Figure 6: Supervision and Incidents under EM

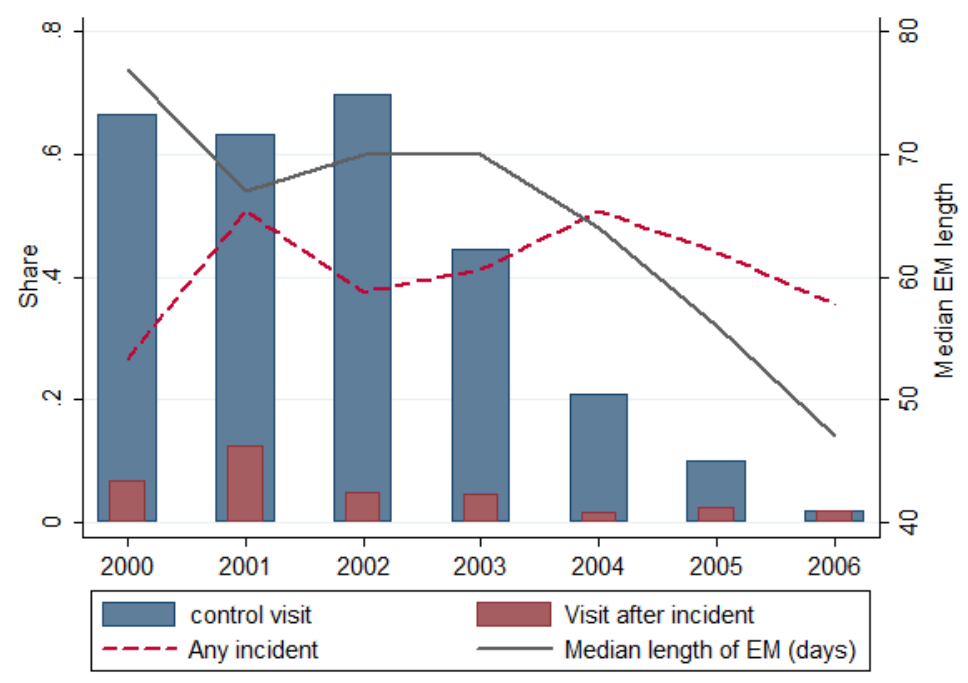

\section{Conclusion}

This article provides new evidence on the effects on future crime of serving a prison sentence at home under electronic monitoring instead of incarceration. To identify causal effects from the use of EM, we exploit the gradual introduction of EM in France, which started as a pilot experiment in four courts (in 2000-2002) before being adopted gradually by an increasing number of courts. 
Our results show that simple comparisons between EM offenders and ex-prisoners highly overestimate the beneficial impact of electronic monitoring on recidivism; the estimated gap in reconviction falls from about 14-15 percentage points to 8-9 pp after including a rich set of control variables. When we also correct for selection based on unobservables, using instruments capturing the staggered introduction of EM across courts over time, the estimated treatment effect falls further to 6-7 percentage points. However, this effect is statistically and economically significant: it implies a reduction in the probability of reconviction of $9 \%$ to $11 \%$. We show that this effect, measured after five years, is not a result of short-term incapacitation at home, and that it applies to a wide range of offenders (note that none of our estimates suggest any criminogenic effect of EM on any subgroup). Actually, EM seems to foster long-term change and desistance from crime, with combined reductions in the probability and seriousness of criminal activity, at a much lower cost than prison.

We also investigate the mechanisms driving our results. First, the beneficial effect of EM is greater on offenders who had already experienced prison, who were required to work under EM, and to a lesser extent on offenders who had children. While these findings confirm that labor-market and social ties are important factors of desistance, they also suggest that EM can maintain specific deterrence among offenders who know what is at stake (most probably, reincarceration) from their own experience. Conversely, the beneficial effect of EM is less prevalent among offenders who serve their first prison sentence at home under EM (instead of incarceration) and is virtually zero when surveillance is not salient (through control visits at home). Overall, we view these results as evidence that EM and incarceration can complement each other and are part of an effective "policy mix": more precisely, EM can achieve significant crime reduction whenever the threat of reincarceration is sufficiently credible and salient.

In terms of public policy, this result has two implications. First, EM may well be 
more effective as a back-door strategy, or as a second sentence after prior incarceration: initial incarceration leads to some level of specific deterrence, while early release under EM offers a second chance for rehabilitation. This interpretation is consistent with the significant crime-reducing effects of EM found in England and Wales (with EM as an early release device) or in Argentina (with EM as an alternative to longer pre-trial detention in very harsh prisons). Second, supervision under EM is key: mild surveillance with no control visits and shorter monitoring periods, which followed the rapid development of EM in France after 2004-2005, are very likely to reduce the benefits of EM. This change in supervision practices inevitably calls into question the effectiveness of EM in France today. 


\section{References}

Abrams, D. S. (2011). Building criminal capital vs. specific deterrence: The effect of incarceration length on recidivism. UC Berkeley Working Paper.

Abrams, D. S. (2013). The imprisoner's dilemma: A cost-benefit approach to incarceration. Iowa Law Review 98, 905-970.

Aebi, M. F. and J. Chopin (2014). Annual penal statistics, space i, survey 2013: Prison populations. Technical report, Council of Europe.

Aizer, A. and J. J. Doyle (2015). Juvenile incarceration, human capital, and future crime: Evidence from randomly assigned judges. The Quarterly Journal of Economics $130(2), 759-803$.

Andersen, L. and S. Andersen (2014). Effect of electronic monitoring on social welfare dependence. Criminology \& Public Policy 13(3).

Aos, S., M. Miller, and E. Drake (2006). Evidence-based public policy options to reduce future prison construction, criminal justice costs, and crime rates. Technical report, Olympia: Washington State Institute for Public Policy.

Bayer, P., R. Hjalmarsson, and D. Pozen (2009). Building criminal capital behind bars: Peer effects in juvenile corrections. The Quarterly Journal of Economics 124(1), $105-147$.

Becker, G. S. (1968). Crime and Punishment: An Economic Approach. Journal of Political Economy 76, 169.

Benaouda, A., A. Kensey, and R. Lévy (2010). La récidive des premiers placés sous surveillance électronique. Cahiers d'études pénitentiaires et criminologiques. 
Bonnemaison, G. (1983). Face à la délinquance: prévention, répression, solidarité. Technical report, Rapport au Premier ministre.

Cabanel, G.-P. (1996). Pour une meilleure prévention de la récidive. Rapport du sénat.

Chen, K. and J. M. Shapiro (2007). Do harsher prison conditions reduce recidivism? a discontinuity-based approach. American Law and Economics Review.

Damm, A. P. and C. Gorinas (2013). Deal drugs once, deal drugs twice : peer effects on recidivism from prisons. In C. Gorinas (Ed.), Essays on Marginalization and Integration of Immigrants and Young Criminals-A Labor Economics Perspective. Aarhus University.

DAP (2015). Les chiffres-clés de l'Administration Pénitentiaire au 1er Janvier 2015. Technical report.

Di Tella, R. and E. Schargrodsky (2013). Criminal recidivism after prison and electronic monitoring. Journal of Political Economy 121(1), 28-73.

Drago, F., R. Galbiati, and P. Vertova (2009). The deterrent effects of prison: Evidence from a natural experiment. Journal of Political Economy 117(2), 257-280.

Drago, F., R. Galbiati, and P. Vertova (2011). Prison conditions and recidivism. American Law and Economics Review 13(1), 103-130.

Durose, M. R., A. D. Cooper, and H. N. Snyder (2014, April). Recidivism of prisoners released in 30 states in 2005: Patterns from 2005 to 2010. Technical report, U.S. Department of Justice, Bureau of Justice Statistics.

Gable, R. K. and R. S. Gable (2005). Electronic monitoring: Positive intervention strategies. Federal Probation 69(1).

Glaze, L. E. and D. Kaeble (2014, December). Correctional populations in the united 
states, 2013. Technical report, U.S. Department of Justice, Bureau of Justice Statistics.

Hjalmarsson, R. (2009, November). Juvenile Jails: A Path to the Straight and Narrow or to Hardened Criminality? Journal of Law and Economics 52(4), 779-809.

Hucklesby, A. (2009, June). Understanding offenders' compliance: A case study of electronically monitored curfew orders. Journal of Law and Society 36 (2), 248-271.

Kensey, A. and A. Benaouda (2011). Les risques de récidive des sortants de prison. une nouvelle évaluation. Cahiers d'études pénitentiaires et criminologiques 36.

Kensey, A. and M. Narcy (2008). Les caractéristiques socio-démographiques des personnes sous pse (2000-2006). Cahiers d'études pénitentiaires et criminologiques.

Kensey, A., A. Pitoun, R. Lévy, and P.-V. Tournier (2003). Sous surveillance électronique. La mise en place du "bracelet électronique" en France (octobre 2000 - mai 2002). Travaux \& Documents (Direction de l'Administration Pénitentiaire).

Kensey, A. and P.-V. Tournier (2005). Prisonniers du passé ? cohorte des personnes condamnées, libérées en 1996-1997 : examen de leur casier judiciaire 5 ans après la levée d'écrou. Direction de l'Administration Pénitentiaire, Travaux et Documents, 348 pages.

Kuziemko, I. (2013). How should inmates be released from prison? An assessment of parole versus fixed-sentence regimes. The Quarterly Journal of Economics 128(1), $371-424$.

Kyckelhahn, T. (2011). Direct expenditures by criminal justice function, 1982-2007. Technical report, Washington, D.C.: Bureau of Justice Statistics.

Landers $\varnothing$, R. (2015). Does incarceration length affect labor market outcomes? Journal of Law and Economics 58(1), 205-234. 
Larsen, B. Ø. (2016). Educational outcomes after serving with electronic monitoring: Results from a natural experiment. Journal of Quantitative Criminology, 1-22.

Lévy, R. and A. Pitoun (2004). L'expérimentation du placement sous surveillance électronique en france et ses enseignements (2001-2004). Déviance et Société.

Marie, O. (2015). Early release from prison on electronic monitoring and recidivism: A tale of two discontinuities. mimeo.

Mastrobuoni, G. and D. Terlizzese (2014). Rehabilitating Rehabilitation : Prison Conditions and Recidivism. EIEF Working Papers Series 1413, Einaudi Institute for Economics and Finance (EIEF).

Mueller-Smith, M. (2014). The criminal and labor market impacts of incarceration. Working paper, Working paper.

National Audit Office (2013). The ministry of justice's electronic monitoring contracts. Technical report.

Ouss, A. (2011). Prison as a school of crime: Evidence from cell-level interactions. Working paper.

Ouss, A. (2013). Sensitivity analysis in economics of crime : Do monitored suspended sentences reduce recidivism? mimeo.

Roman, J. K., A. M. Liberman, S. Taxy, and M. P. Downey (2012, September). The costs and benefits of electronic monitoring for washington, d.c. Technical report, District of Columbia Crime Policy Institute.

Solon, G., S. J. Haider, and J. M. Wooldridge (2015). What are we weighting for? Journal of Human Resources 50(2), 301-316.

Villettaz, P., M. Killias, and I. Zoder (2006). The effects of custodial vs non-custodial 
sentendes on re-offending: A systematic review of the state of knowledge. Technical report, Campbell Systematic Review.

Western, B., J. R. Kling, and D. F. Weiman (2001, June). The labor market consequences of incarceration. Crime and Delinquency 47(3), 410-427. 


\section{Appendix}

\section{Appendix A: Institutional Context}

Figure 7: Map of EM rollout in French courts (2000-2003)

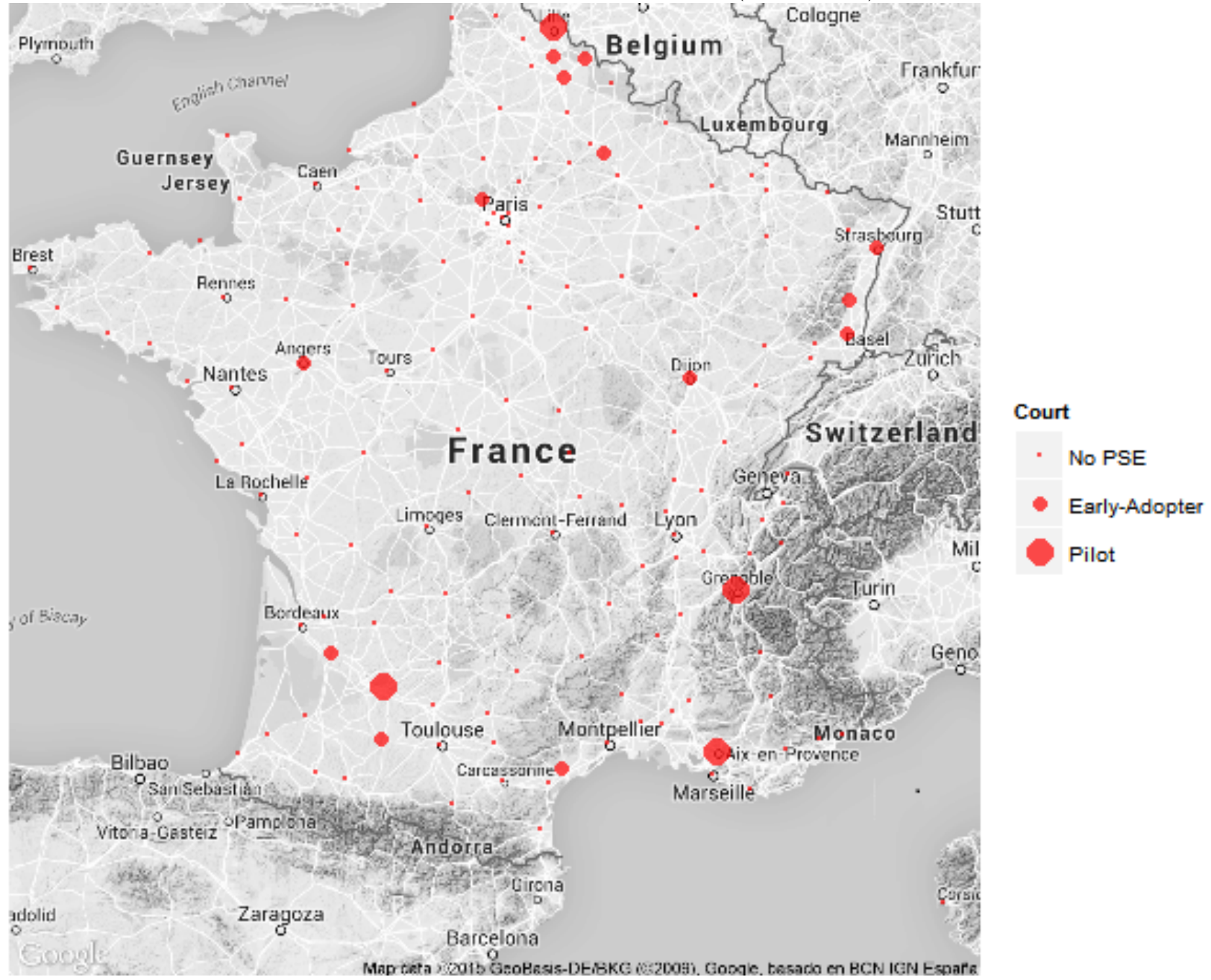




\section{Appendix B: Data and Descriptive Statistics}

Sample restrictions Our initial sample contains 9014 individuals, 515 EM offenders (treated group) and 8499 prisoners (control group). However, we make several sample restrictions to drop those offenders who had clearly no chance of obtaining EM, regardless of its availability in their court.

First of all, many observations are not usable due to death or absence of criminal record for example. Moreover, some individuals exhibit missing values for important variables, such as sentence length. We decided to drop those offenders (43 EM and 1592 prisoners, representing respectively $8.3 \%$ and $18.7 \%$ of the initial samples), leaving us with a sample of 7379 individuals (6907 ex-inmates and 472 ex-EM).

Because having a home was a necessary condition for being placed under EM, we also dropped all ex-inmates who did not have a home when they arrived in prison (981 individuals, $11.5 \%$ of the initial sample). Our sample then contains 6398 individuals, split into 5926 ex-inmates and 472 ex-EM offenders.

A second criterion is required to get EM: offenders should be convicted to a prison sentence of no more than one year. Thus, we discard from our sample the 1973 prisoners (23.2\% of the initial sample) and 11 EM offenders $(2.1 \%)$ who were sentenced to longer periods. The fact that a handful of offenders received EM while convicted for sentences longer than one year (but no more than two years for all of them) is puzzling. One explanation may be a coding error in sentence length, or in the variable for front-door EM (i.e. these 11 offenders actually obtained back-door EM after serving time in prison). This leaves us with a total sample of 4414 individuals, including 3953 ex-prisoners and 461 ex-EM.

We also focus on convicts whose incarceration, if any, took place after final conviction. We conversely drop inmates who were held in pretrial detention, as well as those whose prison sentence started exactly on the day of conviction (bench warrants). Our view is that these prisoners are inherently different from EM offenders, as judges considered that their case required rapid incarceration. Conversely, the very fact that treated offenders obtained EM at home demonstrates that judges did not view them as too dangerous. This major difference leads us to consider as controls only prisoners who were incarcerated strictly after their final prison conviction. 1335 prisoners are dropped ( $15.7 \%$ of the initial sample), leaving a sample of 3079 individuals, with 2618 controls and 461 treated offenders.

Finally, we exclude from most regressions individuals whose follow-up period for new convictions is shorter than five years. This last restriction concerns four EM recipients and 248 inmates $(2.9 \%$ of the initial sample). Our final study sample contains 2827 offenders sentenced to prison, of which 457 received EM directly and 2370 spent time incarcerated. 
Table 6: Sociodemographic and Judicial Variables

\begin{tabular}{|c|c|c|c|c|c|}
\hline Variables & Mean & $\begin{array}{c}\text { Mean } \\
(\mathrm{EM}) \\
(2)\end{array}$ & $\begin{array}{c}\text { Mean } \\
\text { (Prison) } \\
(3)\end{array}$ & Diff. $^{a}$ & $\begin{array}{c}\text { Range } \\
(5)\end{array}$ \\
\hline \multicolumn{6}{|c|}{ Socio-demographic characteristics } \\
\hline Male & $88.3 \%$ & $93.2 \%$ & $87.3 \%$ & *** & {$[0 ; 1]$} \\
\hline $\operatorname{Age}^{\mathrm{b}}$ & 30.6 & 33.2 & 30.1 & $* * *$ & {$[13.6 ; 100.6]$} \\
\hline Standard deviation & $(10.9)$ & $(11.3)$ & $(10.7)$ & & \\
\hline Employment & $41.9 \%$ & $63.9 \%$ & $37.7 \%$ & *** & {$[0 ; 1]$} \\
\hline Couple & $32.0 \%$ & $42.9 \%$ & $29.9 \%$ & $* * *$ & {$[0 ; 1]$} \\
\hline Children & $42.6 \%$ & $50.3 \%$ & $41.1 \%$ & $* * *$ & {$[0 ; 1]$} \\
\hline \multicolumn{6}{|c|}{ Prior sentences to prison } \\
\hline Frequency & $61.5 \%$ & $69.4 \%$ & $60.0 \%$ & *** & {$[0 ; 1]$} \\
\hline Average number & 1.4 & 0.8 & 1.5 & *** & {$[0 ; 27]$} \\
\hline Standard deviation & (2.8) & $(1.8)$ & (2.9) & & \\
\hline \multicolumn{6}{|c|}{ Prior alternative sentences } \\
\hline Frequency & $52.1 \%$ & $50.8 \%$ & $52.4 \%$ & $n s$. & {$[0 ; 1]$} \\
\hline Average number & 1.0 & 1.9 & 0.8 & $* * *$ & {$[0 ; 20]$} \\
\hline Standard deviation & $(1.6)$ & (3.1) & $(1.1)$ & & \\
\hline \multicolumn{6}{|c|}{ Type of initial offense ${ }^{c}$} \\
\hline Acts of Violence & $17.2 \%$ & $18.4 \%$ & $16.9 \%$ & $n s$. & {$[0 ; 1]$} \\
\hline Sexual assaults & $4.6 \%$ & $4.8 \%$ & $4.6 \%$ & $n s$. & {$[0 ; 1]$} \\
\hline Traffic & $20.5 \%$ & $27.1 \%$ & $19.2 \%$ & $* * *$ & {$[0 ; 1]$} \\
\hline Property & $39.0 \%$ & $32.4 \%$ & $40.2 \%$ & $* *$ & {$[0 ; 1]$} \\
\hline Drugs & $10.7 \%$ & $8.5 \%$ & $11.2 \%$ & $\dagger$ & {$[0 ; 1]$} \\
\hline Immigration & $1.9 \%$ & $0.0 \%$ & $2.3 \%$ & $* * *$ & {$[0 ; 1]$} \\
\hline Weapons & $2.0 \%$ & $2.2 \%$ & $2.0 \%$ & $n s$. & {$[0 ; 1]$} \\
\hline \multicolumn{6}{|l|}{ Prison sentence } \\
\hline Initial sentence (months) & 4.8 & 5.4 & 4.6 & *** & {$[0 ; 12]$} \\
\hline Standard deviation & (3.2) & (3.0) & (3.2) & & \\
\hline Early-release & $20.0 \%$ & $0.0 \%$ & $23.8 \%$ & $* * *$ & {$[0 ; 1]$} \\
\hline \multicolumn{6}{|c|}{ Prison characteristics } \\
\hline \multicolumn{6}{|l|}{ Prison type ${ }^{\mathrm{d}}$} \\
\hline Maison d'arrêt & $78.3 \%$ & $80.1 \%$ & $78.0 \%$ & $n s$. & {$[0 ; 1]$} \\
\hline Centre de détention & $21.7 \%$ & $19.9 \%$ & $22.0 \%$ & $n s$. & {$[0 ; 1]$} \\
\hline Overcrowding rate & $111.7 \%$ & $113.5 \%$ & $111.3 \%$ & $n s$. & {$[26.6 \% ; 250 \%]$} \\
\hline Standard deviation & $(33.9 \%)$ & $(30.3 \%)$ & $(34.6 \%)$ & & \\
\hline \multicolumn{6}{|c|}{ Recidivism after 5 years (weighted for oversampling) } \\
\hline Any reconviction & $65.4 \%$ & $46.2 \%$ & $66.2 \%$ & *** & {$[0 ; 1]$} \\
\hline Reconviction to prison & $54.0 \%$ & $29.8 \%$ & $55.0 \%$ & $* * *$ & {$[0 ; 1]$} \\
\hline Sample Size & 2827 & 457 & 2370 & & \\
\hline \multicolumn{6}{|c|}{$\begin{array}{l}\text { The sample is composed of offenders who had a home and who started serving their sentence (in } \\
\text { prison or under EM) strictly after their date of conviction. }{ }^{\dagger} \mathrm{p}<10 \%,{ }^{*} \mathrm{p}<5 \%,{ }^{* *} \mathrm{p}<1 \%,{ }^{* * *} \mathrm{p}<0.1 \% \text {. } \\
\text { a Column (4) shows two-sample t-tests between EM group and prison group. } \\
\text { b Age at the beginning of the sentence (age at incarceration for ex-inmates or age at EM). } \\
\text { c "Acts of violence" include homicides, assault and battery, contempt of court and disrespect for police. } \\
\text { "Sexual assaults" include rapes, sexual assaults, offenses against honor and indecencys. "Traffic" } \\
\text { includes drunk-driving and other common offenses (speeding, driver's license-related violations, etc.). } \\
\text { "Property" includes all kinds of thefts and robberies, destruction and fraud. }\end{array}$} \\
\hline
\end{tabular}




\section{Appendix C: Exploring the gradual rollout of EM in France}

Table 7: Number of EM executed across courts by April $1^{\text {st }}$
\begin{tabular}{|l|c|}
\hline Court Name & EM executed \\
\hline Agen & 93 \\
Aix-en-Provence & 105 \\
Grenoble & 108 \\
Lille & 90 \\
$\quad$ Total Pilot courts & $\mathbf{3 9 6}$ \\
& \\
Béziers & 25 \\
Dunkerque & 13 \\
Pontoise & 13 \\
Cambrai & 5 \\
Auch & 4 \\
Valenciennes & 4 \\
Douai & 3 \\
Colmar & 2 \\
Dijon & 2 \\
Strasbourg & 2 \\
Hazebrouck & 1 \\
Marmande & 1 \\
Reims & 1 \\
Total Early-adopter courts & $\mathbf{7 6}$ \\
\hline Total & $\mathbf{4 7 2}$ \\
\hline
\end{tabular}

Note that all French courts that are not listed here did not issue any EM devices during the 2000-2003 period, and are labelled as late adopters. 


\section{Appendix D: Testing for the endogenous selection of EM by courts}

Table 8: Differences in Five-year Recidivism Before the Introduction of EM

\begin{tabular}{|c|c|c|c|c|}
\hline & \multicolumn{2}{|c|}{2002 cohort } & \multicolumn{2}{|c|}{ 1996-97 cohort } \\
\hline Pilot court & $\begin{array}{c}0.0203 \\
(0.0392)\end{array}$ & $\begin{array}{l}-0.0296 \\
(0.0384)\end{array}$ & $\begin{array}{c}0.0350 \\
(0.1104)\end{array}$ & $\begin{array}{c}0.0031 \\
(0.0587)\end{array}$ \\
\hline Early-adopter court & $\begin{array}{c}0.0037 \\
(0.0401)\end{array}$ & $\begin{array}{l}-0.0002 \\
(0.0219)\end{array}$ & $\begin{array}{c}0.0015 \\
(0.0529)\end{array}$ & $\begin{array}{l}-0.0027 \\
(0.0404)\end{array}$ \\
\hline Ref: late-adopters & 0 & 0 & 0 & 0 \\
\hline Initial sentence length & $\mathrm{x}$ & $\mathrm{x}$ & & \\
\hline Stratification vars. & & $\mathrm{x}$ & & \\
\hline Demographics & & $\mathrm{x}$ & & $\mathrm{x}$ \\
\hline Past convictions & & $\mathrm{x}$ & & $\mathrm{x}$ \\
\hline $\mathrm{N}$ & 2270 & 2270 & 2207 & 2207 \\
\hline
\end{tabular}

The table reports Average Marginal Effects (robust s.e. clustered at court level) from Probit regressions of 5-year recidivism on two dummies for type of court. Columns 2 and 4 include the same large set of additional control variables as in Table 2. The 2002 sample only includes prisoners who were incarcerated before EM was legally available in their court (Oct 1, 2000 in pilot courts; Jan 1, 2002 in other courts): to account for this difference in sample restrictions, initial sentence length is controlled for as a second-degree polynomial. The 1996-1997 sample includes all prisoners, who are matched to the future type of their corresponding court, based on the location of their prison. ${ }^{\dagger} \mathrm{p}<10 \%,{ }^{*} \mathrm{p}<5 \%,{ }^{* *} \mathrm{p}<1 \%,{ }^{* * *} \mathrm{p}<0.1 \%$ 
Figure 8: Prison overcrowding rates on January 1
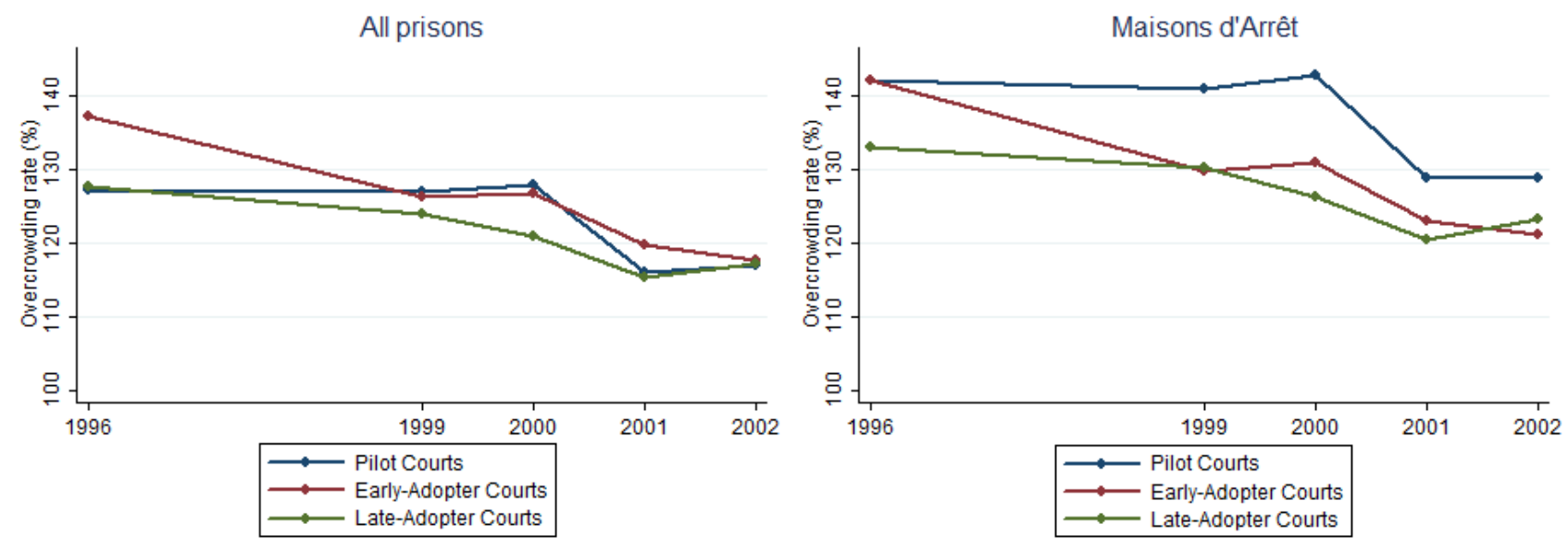

Figure 9: Rates of Property Crime (left) and Violent Crime (right)
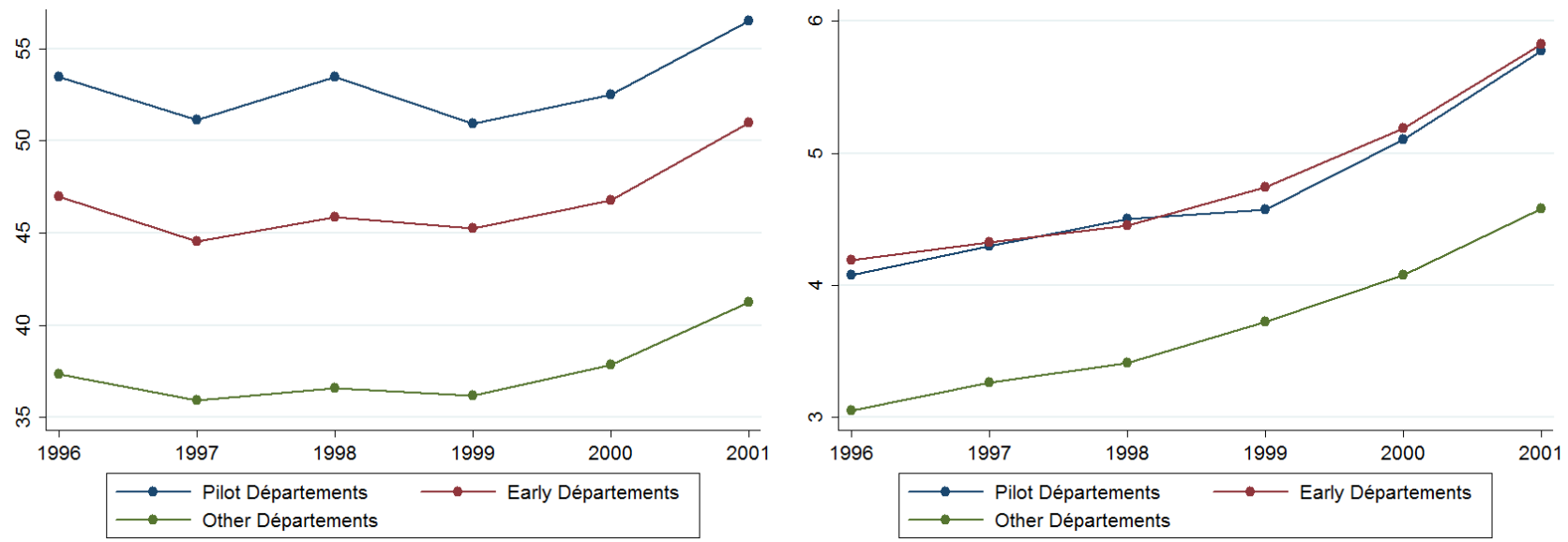


\section{Appendix E: Robustness Checks and Discussion}

Table 9: Robustness: Electronic Monitoring and Recidivism

\begin{tabular}{lcc}
\hline \hline & Probit & Bi-Probit \\
\hline 100km neighboring courts & $-0.0937^{* *}$ & $-0.0768^{*}$ \\
$\mathrm{~N}=1666$ & $(0.0309)$ & $(0.0390)$ \\
\hline Local crime rate (level +2 year change) & $-0.0857^{* *}$ & $-0.0749^{*}$ \\
$\mathrm{~N}=2716$ & $(0.0314)$ & $(0.0372)$ \\
\hline Released $3 / 1 / 2002-3 / 31 / 2003$ & $-0.0783^{* *}$ & $-0.0658^{+}$ \\
$\mathrm{N}=2578$ & $(0.0301)$ & $(0.0345)$ \\
\hline Alt. Starting Date & & \\
$\mathrm{N}=2754$ & $-0.0868^{* *}$ & $-0.0753^{*}$ \\
\hline Instr: only courts with $>20$ convicts & $(0.0281)$ & $(0.0337)$ \\
$\mathrm{N}=2408$ & $-0.0896^{* *}$ & $-0.0789^{*}$ \\
\hline Instr: Pilot, early-adopter & $(0.0289)$ & $(0.0345)$ \\
$\mathrm{N}=2827$ & $-0.0832^{* *}$ & $-0.0696^{*}$ \\
\hline \hline
\end{tabular}

Robust standard errors in parentheses, clustered at court level. ${ }^{+} p<0.1 ;{ }^{*} p<0.05 ;{ }^{* *} p<0.01$ $;^{* * *} p<0.001$. All regressions include the full set of control variables. Average Marginal Effects reported.

Figure 10: Density of Date of Release

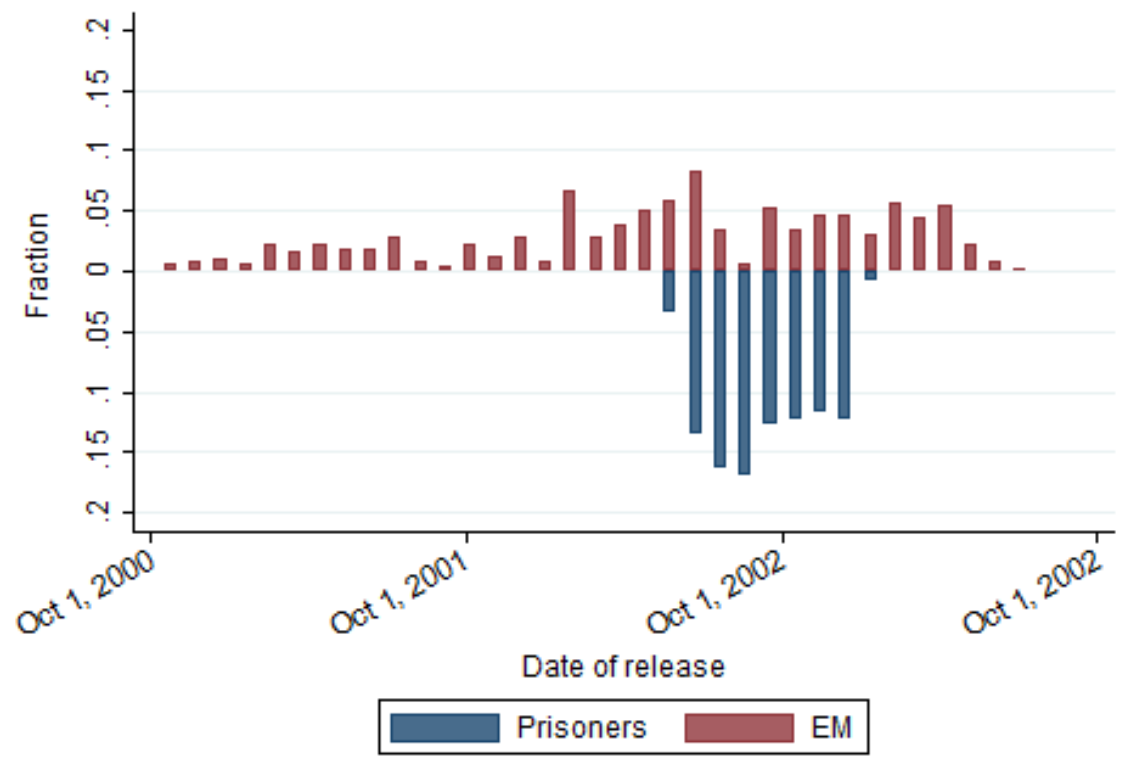


Figure 11: Evolution of Aggregate Recidivism as Courts Adopt EM

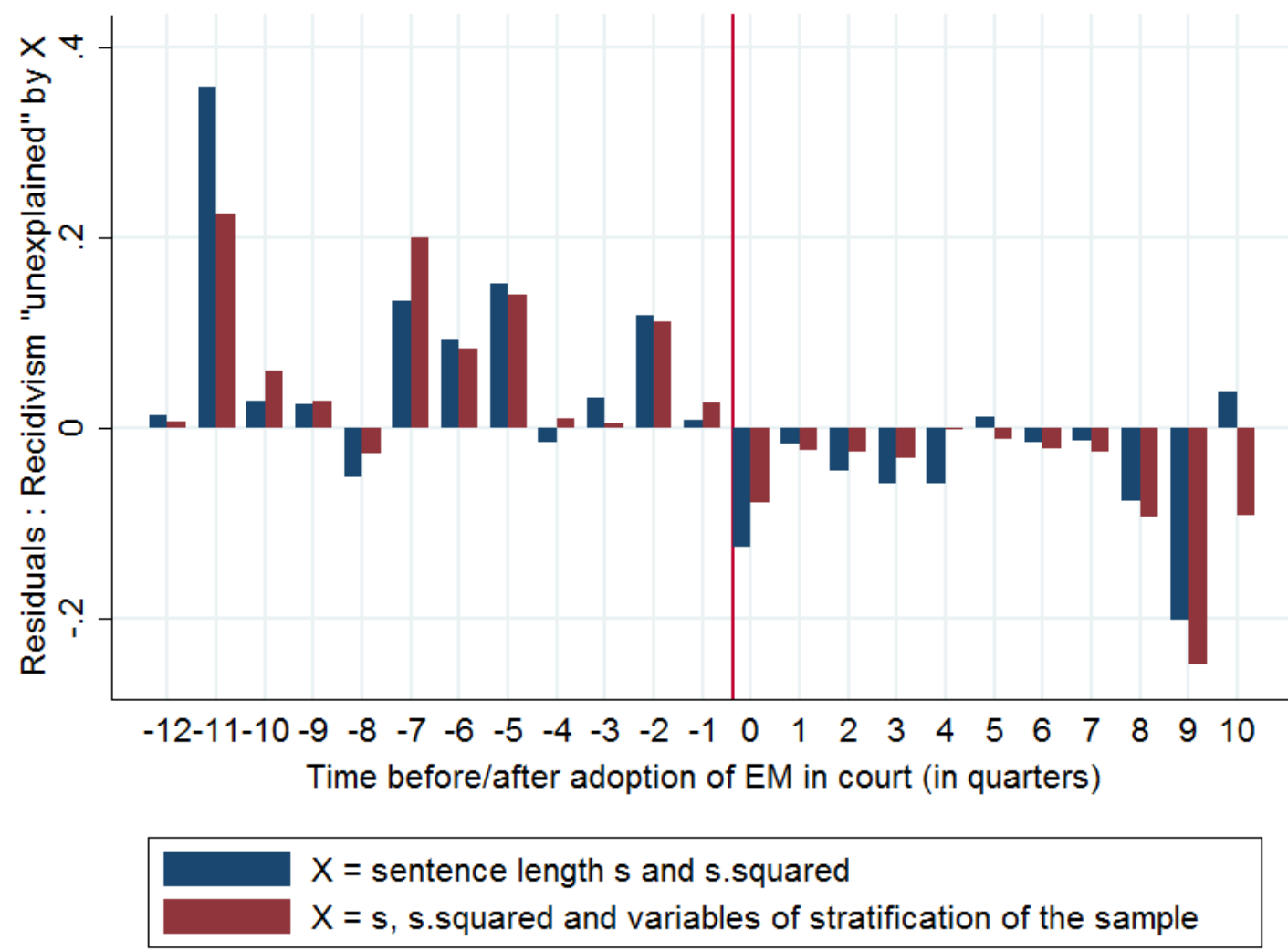


Table 10: Crime-specific effects

\begin{tabular}{lccc}
\hline \hline & \multicolumn{3}{c}{ Type of New Crime } \\
& Property & Traffic & Other \\
\hline \multirow{2}{*}{ ElectronicMonitoring } & -0.0028 & $-0.0322^{+}$ & -0.0226 \\
& $(0.0214)$ & $(0.0176)$ & $(0.0170)$ \\
& & & \\
\hline $\mathrm{N}$ & 2827 & 2827 & 2827 \\
Recidivism Rate & $17 \%$ & $16 \%$ & $20 \%$ \\
Estimated \% EM effect & $(-2)$ & -21 & $(-11)$ \\
\hline \hline
\end{tabular}

Robust standard errors in parentheses, clustered at court level. ${ }^{+} p<0.1 ;{ }^{*} p<0.05 ;{ }^{* *} p<0.01$; ${ }^{* * *} p<0.001$. Crime-specific estimates are obtained simultaneously by 3SLS to achieve convergence. All regressions include the full set of control variables and correct for endogeneity of EM using the same instruments.

To investigate the effect of EM on crime types, we classify new offenses in three categories with high recidivism rates: property crimes (17\% recidivism), traffic offenses (16\%) and others such as assaults, drug-related offenses, etc. (20\%). We estimate these three (non-mutually-excluding) crime-specific probabilities on EM treatment simultaneously by Three Stage Least Squares.

Table 11: Marginal effectiveness

\begin{tabular}{lcc}
\hline \hline \multicolumn{2}{l}{ Number of previous EM in court } & \\
& $<50 \mathrm{EM}$ & $\geq 50 \mathrm{EM}$ \\
\hline & & \\
ElectronicMonitoring & -0.0610 & $-0.0666^{+}$ \\
& $(0.0392)$ & $(0.0394)$ \\
$\rho$ & & \\
$\mathrm{N}$ & $0.0094(0.1149)$ & $-0.3125^{* *}(0.1022)$ \\
\hline \hline
\end{tabular}

Robust standard errors in parentheses, clustered at court level. ${ }^{+} p<0.1 ;{ }^{*} p<0.05$; ${ }^{* *}$ $p<0.01 ;{ }^{* * *} p<0.001$. The table reports Average Marginal Effects after bivariate probit, using CourtEverUsedEM as IV (second instrument not significant). 